\title{
Canadian Urological Association guideline: Management of ureteral calculi - Full-text
}

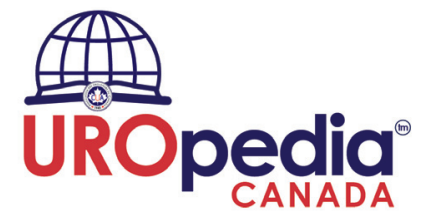

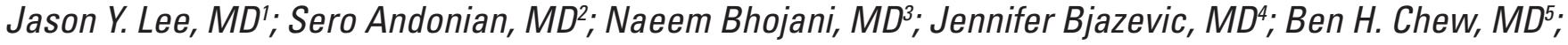
Shubha De, MD'; Hazem Elmansy, MD'; Andrea G. Lantz-Powers, MD'; Kenneth T. Pace, MD'; Trevor D. Schuler, MD'; Rajiv K. Singal, MD'; Peter Wang, MD'; Michael Ordon, MD ${ }^{10}$

'Division of Urology, Department of Surgery, University of Toronto, Toronto, ON, Canada; ${ }^{2}$ Division of Urology, Department of Surgery, McGill University Health Centre, Montreal, QC, Canada; ${ }^{3}$ Department of Urology, Université de Montréal, Montreal, QC, Canada; ${ }^{4}$ Division of Urology, Department of Surgery, Western University, London, ON, Canada; ${ }^{5}$ Department of Urologic Sciences, University of British Columbia, Vancouver, BC, Canada; ${ }^{\circ}$ Division of Urology, Department of Surgery, University of Alberta, Edmonton, AB, Canada; ${ }^{7}$ Urology, Northern Ontario School of Medicine, Thunder Bay, ON, Canada; ${ }^{8}$ Department of Urology, Dalhousie University, Halifax, NS, Canada; ' 2 London Health Sciences Centre, Western University, London, ON, Canada; ${ }^{10}$ Division of Urology, Department of Surgery, University of Toronto, Toronto, ON, Canada
\end{abstract}

\section{Reviewer: John Dushinski, MD}

Southern Alberta Institute of Urology, Calgary, AB, Canada

Cite as: Lee JY, Andonian S, Bhojani N, et al. Canadian Urological Association guideline: Management of ureteral calculi - Full-text. Can Urol Assoc J 2021;15(12):E676-90. http://dx.doi.org/10.5489/cuaj.7581

Published online August 21, 2021

See related commentary at cuaj.ca

\section{Introduction}

Globally, the prevalence of urolithiasis is steadily increasing, and though some regional variability exists, contemporary estimates report up to $10-12 \%$ of men and $7-8 \%$ of women now suffer from nephrolithiasis. ${ }^{1-3}$

Renal colic is one of the most frequent and expensive emergency department (ED) presentations. ${ }^{1,2}$ A study comparing renal colic management patterns in two Canadian cities identified widely varying trends in care, with admission rates as high as $60 \%$, and surgical intervention rates over $50 \%$. Though early intervention has been purported to allow patients to return back to normal life sooner, it appears early intervention led to increased subsequent ED visits, re-admissions, and secondary procedures. ${ }^{4}$ Another study looking at costs associated with management of acute renal colic found that an initial trial of non-surgical management was associated with lower indirect costs. ${ }^{5}$

The aim of this Canadian Urological Association (CUA) guideline document is to provide evidence-based consensus recommendations on various aspects relevant to the management of ureteral stones; the major topic areas included were conservative management, medical expulsive therapy, shockwave lithotripsy (SWL), ureteroscopy (URS), and special clinical scenarios (e.g., pregnancy, pediatrics).

\section{Methods}

Separate reviews of the literature were performed for each of the major topic areas. English-language publications were identified from PubMed/Medline, with a focus on recent publications since our last CUA guideline document on ureteral stones published in 2015. ${ }^{6}$ The 2011 University of Oxford Centre for Evidence-Based Medicine Levels of Evidence grading system was used to evaluate the level of evidence of recommendations included in the document. ${ }^{7}$ All recommendations were based on expert review of the literature and represent the consensus of all authors of this guideline document.

\section{Conservative management of ureteral stones}

Non-operative management remains a reasonable first-line approach for most patients presenting with ureteral stones. A 2010 meta-analysis of 37 studies demonstrated that $38-71 \%$ of symptomatic ureteral stones $<4 \mathrm{~mm}$ would pass spontaneously. ${ }^{8}$ As well, looking at the placebo control arms of several large randomized controlled trials (RCTs) evaluating the efficacy of medical expulsive therapy (MET), spontaneous passage rates range from $40-80 \%$ for stones $<10 \mathrm{~mm} \cdot{ }^{9-11}$ Clearly, an initial course of conservative management seems reasonable for many.

The urologist is often called upon in the setting of a suspected "septic stone" - conservative management is not 
an option in this setting. With a sufficient index of suspicion, early goal-directed therapy, including blood and urine cultures, broad-spectrum intravenous antibiotics, resuscitation, and source control is paramount. Decompression of an obstructed pyelonephritis reduces mortality ${ }^{12}$ and avoiding delays can prevent prolonged hospital admissions. ${ }^{13}$ The method of drainage should be tailored to the patient's clinical scenario and stone characteristics, as well as to the available resources at each center. ${ }^{14,15}$ In the only prospective, randomized trial, patients presenting with a fever $>38^{\circ} \mathrm{C}$, leukocytosis, and obstructing stone $<15 \mathrm{~mm}$ were randomized to either a ureteric stent or a nephrostomy tube (NT). ${ }^{16}$ There were no differences in any clinical outcome evaluated, including time to defervescence, duration of hospital stay, and resolution of obstruction. Other studies have also found that timely decompression is paramount, regardless of method. ${ }^{17-19}$ It is generally agreed that definitive treatment should not be undertaken until the obstructed system has been decompressed and the infection adequately treated. Although, there is no strong evidence as to how long to wait after initial treatment, one study recommends a minimum of seven days before definitive treatment. ${ }^{20}$

While patients with true urosepsis (life-threatening organ dysfunction caused by a dysregulated response to a genitourinary [GU] infection ${ }^{21}$ are more easily identified, accurately diagnosing pre-septic patients with a concomitant urinary tract infection (UTI) and an obstructing stone may not be as clear. Irritative lower urinary tract symptoms, hematuria, and pro-inflammatory urine/blood markers have led to inconsistent interpretation about the presence of infection and ultimately antibiotic use. ${ }^{22}$ Many patients are inappropriately given antibiotics and there is an opportunity to improve clinical practice and antibiotic stewardship with some continued medical education initiatives.

Acute kidney injury (AKI) is present in approximately $6 \%$ of patients presenting with renal colic. ${ }^{23}$ When significant renal impairment accompanies ureteral stones, early decompression or definitive therapy may mitigate further deterioration. Early intervention may also be indicated if the patient with a ureteral stone presents with intractable symptoms (pain, nausea, etc.) or significant frailty/comorbidities.

There is limited data supporting early surgical intervention rather than a period of initial conservative therapy, with one RCT demonstrating that early ureteroscopic management $(<12$ hours after ED admission) led to similar stone-free and complication rates but lower rates of postoperative stenting. ${ }^{24}$ Two RCTs looking at early SWL ( $<48$ hours) vs. delayed SWL (2-7 days) demonstrated earlier time to stone-free status, fewer required treatments, and perhaps lower complications in the early SWL arms. ${ }^{25,26}$ Importantly, these studies had a high risk of bias, highlighted by the fact that spontaneous stone passage rates in the delayed intervention arms of these RCTs was only $0-5.4 \%$.
Recommendation: Many patients with ureteral stones can initially be managed non-operatively, as spontaneous passage rates are high, particularly for smaller stones $(<5$ $\mathrm{mm})$. Close followup is necessary for those being managed conservatively, to ensure spontaneous stone passage or to decide upon the need for timely intervention (level 2, strong recommendation). Obstructive pyelonephritis requires early goal-directed therapy, including timely decompression in an antegrade or retrograde fashion, whichever method is most expedient (level 2, strong recommendation).

\section{Imaging}

Use of computed tomography (CT) scans have increased by over 10 -fold in recent years, ${ }^{27}$ being performed in $90 \%$ of those diagnosed with urolithiasis in the acute setting, whereas ultrasonography (US) is used in less than $7 \%$ of these patients. ${ }^{28}$ There is evidence to suggest patient gender may impact initial imaging modality selected. ${ }^{29,30}$ A large, randomized trial comparing initial imaging modalities for renal colic presentations in the ED found most clinical outcomes were equivalent between US and non-contrast CT (NCCT) imaging, recommending initial US given the lack of radiation exposure. ${ }^{28}$ In this RCT, USs performed by radiologists, compared to point-of-care US (POCUS) were less likely to result in followup CT scans, but did increase visit times within the ED. ${ }^{31}$ While POCUS is convenient, it is more operator-dependent and consulting teams often have no images or formal report to review. Details founds on a NCCT are often, but not always, required for definitive stone management and followup, particular for complex scenarios.

Supplementing US with kidney-ureter-bladder (KUB) $\mathrm{X}$-rays can enhance the sensitivity of detecting a ureteral stone. Studies demonstrate that combining these modalities results in sensitivity ranging from $79-100 \%$ and specificity up to $100 \% .^{32}$ One study also demonstrated that the addition of a formal KUB X-ray, even when CT scout images were available, improved followup diagnostic accuracy. ${ }^{33}$ Obtaining a KUB X-ray at the time of a diagnostic imaging in the $\mathrm{ED}$ is useful for not only determining stone composition, but also to track the progress of stone passage in followup.

Reduced-dose NCCT scans have been shown to maintain sensitivities and specificities from 90-97\%, while preserving enough detail to identify alternate diagnoses. When assessing for stones specifically, body mass index (BMI) has been shown to be less of a concern, with $>95 \%$ diagnostic accuracy and radiation doses $<3.7 \mathrm{mGy}$ regardless of BMI. ${ }^{34}$ Though dual-energy CT scans have shown utility in identifying uric acid stone composition, ${ }^{35}$ there is little additional benefit in the acute setting, as obstructing stones are not typically treated with dissolution therapy.

Overall, while adhering to as-low-as-reasonably-achievable (ALARA) radiation exposure principles, the patient's 
age, pregnancy status, stone history, and preceding exposure to ionizing radiation should be considered whenever ordering imaging for non-life-threatening indications. An overreliance on $\mathrm{CT}$ imaging has been identified and should be addressed in our practice patterns.

Recommendation: Ultrasonography with KUB X-ray should be considered the initial modality of choice for acute ureteral stones. Judicious use of CT scans, preferably low-dose, provides valuable information for management decisions (level 1, strong recommendation). While often omitted, the utility of a KUB X-ray at the time of presentation is very important for future followup and decision-making regarding definitive treatment options (level 4, expert opinion).

\section{Discharge planning}

\section{Medical expulsive therapy (MET)}

Recently, several large RCTs $s^{11,36,37}$ failed to show improved stone passage rates or reduced analgesic requirements when using alpha-blockers for MET. However, several published meta-analyses ${ }^{38-40}$ suggest overall benefit of MET for ureteral stones. Subgroup analysis data suggests this benefit may be mainly for larger $(5-10 \mathrm{~mm})$, distal ureteral stones. . $^{36,37,40-42}$ A Cochrane review of 67 studies analyzed all studies, specifically looking at lower- and higher-quality studies. The higher-quality, placebo-controlled studies showed a benefit with MET (relative risk [RR] 1.16, 95\% confidence interval [CI] 1.07-1.25), a decrease in hospitalizations (RR 0.51, $95 \% \mathrm{Cl} 0.34-0.77$ ), and no significant changes in the need for intervention. ${ }^{43}$

\section{Analgesia}

Moving away from a reliance on opioids in acute care patients with renal colic is important and these patients have been found to do well with non-opiate analgesia. ${ }^{44}$ In one study, 1500 adult acute care patients were randomized to intramuscular diclofenac, intravenous morphine, or intravenous paracetamol. At 30 minutes, non-steroidal anti-inflammatories (NSAIDs) were more effective in reducing pain by $50 \%$ compared to morphine, with no adverse events. ${ }^{45}$ Another randomized trial showed protocoled nonopioid analgesia could reduce opioid requirements during initial presentation if first- and second-line interventions included NSAIDS and intravenous lidocaine. However, opioid-sparing approaches were associated with higher rates of repeat visits to the ED. ${ }^{46}$ Discharge prescriptions can vary significantly based on the patient population and comorbidities. Accounting for important patient characteristics (e.g., post-traumatic stress disorder, anxiety/depression, chronic pain syndromes) when prescribing analgesia for acute renal colic is also important. ${ }^{47,48}$

\section{Forced hydration}

While there is clear utility in re-hydrating hypovolemic patients with significant nausea and vomiting, or in those with a suspected pre-renal AKI, intravenous (IV) hydration for the sole purpose of forced stone passage is not supported by the literature and should be avoided. ${ }^{49}$

Recommendation: The role of MET in promoting spontaneous passage is controversial, but the current literature suggests if there is any benefit, it is for larger $(5-10 \mathrm{~mm})$ ureteral (distal) stones. The advantages and disadvantages of MET should be discussed with the patient in a shared decision-making process (level 1 , strong recommendation). The use of opioid-sparing analgesic regimens has been shown to be efficacious and opioids for management of renal colic should be minimized; patient education is paramount (level 1, strong recommendation). Forced IV hydration for the purposes of stone expulsion is not recommended (level 1 , moderate recommendation).

\section{Renal colic followup}

Unfortunately, neither resolution of symptoms nor patient reports of successful passage of obstructing ureteral stones is always confirmatory. One study demonstrated that $6.2 \%$ of patients reporting passage of a symptomatic ureteral stone had persistent obstruction on followup CT scan imaging. ${ }^{50}$ Another study demonstrated that resolution of pain was only $79.7 \%$ sensitive and $55.8 \%$ specific for successful passage of a ureteral stone, based on followup US and KUB X-ray imaging. ${ }^{51}$ As such, followup imaging to ensure passage of an obstructing ureteral stone is suggested. The ideal imaging modality of choice remains uncertain, but one study found that $38 \%$ of patients with a persistent ureteral stone, confirmed on ultra-low-dose $\mathrm{CT}$, had neither hydronephrosis on CT nor a visible stone on the CT scout image. ${ }^{52}$

Data suggests the majority of patients that will pass ureteral stones spontaneously will do so within approximately one month of presentation. ${ }^{11,33-34}$ Examining the literature on long-term renal damage and ureteral obstruction, it is difficult to elucidate an objectively safe or unsafe duration of observation for a ureteral stone where no imperative indication for treatment exists; the data is mainly from animal studies and usually involves a complete obstruction model. While degree and duration of obstruction are clearly important, other factors unique to each patient also need to be considered: poor baseline renal function, older age, male gender, and presence of certain comorbidities (e.g., diabetes) have been associated with increased risk of chronic kidney disease. ${ }^{53,54}$

Recommendation: Resolution of symptoms and patientreported stone passage after a bout of renal colic do not always confirm passage of an obstructing ureteral stone. 
Followup imaging is recommended to confirm stone passage (level 3, strong recommendation). The recommended duration of conservative management is unique to each patient, with multiple factors to be considered. Surgical intervention should likely be considered if a patient has not passed an obstructing ureteral stone after 4-6 weeks (level 5 , moderate recommendation).

\section{Shockwave lithotripsy}

Despite the advances in ureteroscopes and laser technologies, SWL remains a first-line treatment option for ureteral calculi. SWL outcomes can be directly influenced by case selection, surgeon technique, and modifiable parameters to enhance safety and maximize successful outcomes. Much of the data for SWL outcomes is derived from patients with renal calculi, but these findings should be generalizable to ureteric stones, particularly for those in the upper ureter, where renal parenchyma is included in the shockwave path.

\section{Clinical factors affecting SWL treatment success}

\section{Composition}

The majority of stones are composed of calcium oxalate and most will fragment well with SWL treatment. There are certain stone compositions, such as cystine, pure calcium oxalate monohydrate, and brushite, that are more resistant to SWL and may be better served by ureteroscopic management. ${ }^{55}$ Uric acid stones, while fragile in the face of SWL, require either the use of ultrasound or pyelography (intravenous or retrograde) for targeting during SWL.

\section{Stone density}

Stone density, as measured on NCCT scan in Hounsfield units $(H U)$, has been shown to predict successful SWL outcomes. A crude surrogate for composition, a linear relationship exists between increased stone density and poor stone fragmentation with a threshold of $1000 \mathrm{HU}$, above which stones are less likely to be successfully fragmented. ${ }^{56-60}$ The variation coefficient of stone density (VCSD), which is a measurement of stone heterogeneity on CT scan and reflects the crystal architecture of the stone, has been reported as a novel predictor of SWL success and may outperform HU as a predictor of success; however, further study in this measurement would be useful. ${ }^{61}$

\section{Skin-to-stone distance (SSD)}

A longer SSD has been associated with reduced treatment success for SWL for renal ${ }^{62-67}$ and ureteral stones, ${ }^{65}$ with SSD greater than $10 \mathrm{~cm}$ often associated with decreased stone-free rates (SFRs).

Recommendation: Stone size, location, composition, density, and SSD can help counsel patients regarding the suc- cess rates of SWL treatment. Known uric acid, cystine, and brushite stones are likely best treated with URS (level 4, moderate recommendation). Patients with ureteral stones with a density $>\mathbf{1 0 0 0} \mathrm{HU}$ or SSD $>\mathbf{1 0} \mathrm{cm}$ have lower SFRs with SWL (level 2, strong recommendation) and shared decision-making with patients is important to balance the availability, morbidity, and efficacy of SWL vs. URS.

\section{Optimizing treatment outcomes}

\section{Dose escalation/pause}

Gradually increasing SWL energy up to optimal dose allows for better patient accommodation to the sensation of treatment and, for upper ureteral stones, reduces renal injury by inducing renal vasoconstriction. ${ }^{68-72}$ An alternative strategy is to pre-treat with a series of low-energy shocks, then pause treatment for a short period of time before resuming at higher-energy levels. ${ }^{68}$

\section{Number of treatments}

If SWL is not successful, it can be repeated, but the incremental benefit of more than two treatments for the same ureteric stone is small. ${ }^{73,74}$ The optimal time interval between SWL treatments is unclear but can be short (2-3 days) for mid and distal ureteral stones.

\section{Treatment rate}

Several randomized trials have indicated that a lower shock rate can improve stone fragmentation, particularly for stones larger than $1 \mathrm{~cm}$. The optimal treatment rate is not clear, however, studies suggest that SWL at 60-90 shocks/minute leads to better fragmentation than 120 shocks/minute, particularly for larger stones. ${ }^{75-83}$ Most studies were performed with renal calculi, however, improved outcomes have been demonstrated for upper ureteric stones as well. ${ }^{76}$

\section{Number of shocks}

The optimal number of shocks has not been definitively established but requires balancing treatment efficacy with adverse effects, particularly renal damage. For upper ureteral stones, the recommended shock rate range is 2000-3500, but manufacturer's guidelines should be closely considered..$^{74}$ For mid to distal ureteric stones, where the renal parenchyma is not affected by SWL energy, treatment can safely be carried out up to 4000 or more shocks. ${ }^{74}$ Some studies have assessed the efficacy and safety of increasing the number of shockwaves per session to $>4000 . .^{84,85}$

Recommendation: Patients with upper ureteric stones should initially receive low-energy shocks, with gradual voltage escalation up to maximum energy (level 2, strong recommendation). If unsuccessful, repeat SWL can be considered but more than two treatments to the same ureteric 
stone has little incremental benefit and URS should then be considered (level 4, moderate recommendation). Patients with upper ureteric stones $>1 \mathrm{~cm}$ or those selected for retreatment after initial failed $S W L$, should be treated at a rate $<120$ shocks/minute for optimal fragmentation (level 1 , strong recommendation). An adequate number of shocks (2000-4000 for most lithotripters) should be administered to ensure adequate treatment of ureteric stones (level 4 weak recommendation). A higher number of shocks may result in improved SFRs, but data is limited to make this a recommendation for routine practice.

\section{Alpha-blockers}

Alpha-blockers (most commonly tamsulosin) have been studied to assess their impact on SWL outcomes in multiple RCTs and meta-analyses. ${ }^{86-95}$ Meta-analyses have shown improved SWL success rates, ${ }^{89,94-96}$ time to stone passage, risk of steinstrasse, ${ }^{93-96}$ and need for auxiliary procedures ${ }^{93}$ A recently published Cochrane systematic review demonstrated routine alpha-blocker therapy may result in improved stone clearance, less need for auxiliary treatments, fewer major adverse events, and a reduced stone clearance time. ${ }^{97}$ Additional benefits with respect to pain and analgesic use are also of interest.

\section{Stenting}

Routine pre-SWL stenting is not necessary and does not improve the success rate or passage of fragments. ${ }^{98-101}$ In fact, having a stent may impede the passage of fragments following SWL and does not appear to decrease the risk of steinstrasse or infection, ${ }^{100-104}$ with the possible exception of steinstrasse risk for stones $>2 \mathrm{~cm} .{ }^{100}$ Stents may be beneficial for obstructing stones, if relief of obstruction is warranted prior to treatment (e.g., obstruction with infection, renal failure, intolerable pain), and prior to SWL for stones in a solitary kidney. ${ }^{105}$

Recommendation: Alpha-blockers (e.g., tamsulosin) should be prescribed after SWL for ureteral stones to improve treatment success rates (level 1, moderate recommendation). Ureteral stents do not improve SFRs after SWL and do not reduce the risk of steinstrasse or infection following SWL for most patients (i.e., stones $<\mathbf{2} \mathbf{~} \mathbf{~ m}$ ) (level 1, moderate recommendation).

\section{Ureteroscopy}

Modern URS is a mainstay in the surgical treatment of ureteral stones worldwide. As a result of advancements in technology in recent decades, URS can be safely performed with high SFR and relatively low complications.

\section{Preoperative alpha-blockers}

The use of alpha-blockers prior to URS appears to improve intraoperative outcomes and patient SFR. A recent systematic review and meta-analysis comprising of 12 RCTs and 1352 patients evaluated alpha-blocker use before planned URS for the management of ureteral calculi. ${ }^{106}$ With a median preoperative use of one week, a $61 \%$ risk reduction in need for ureteral dilatation was observed. Furthermore, the use of preoperative alpha-blockers significantly improved SFR (RR $1.18,95 \% \mathrm{Cl} 1.11-1.24, \mathrm{p}<0.00001)$, reduced operative time by an average of six minutes $(p=0.004)$, and decreased patient hospital stay $(p=0.001)$. Whether one week of use is optimal or simply convenient for patients was not defined. Larger, more appropriately powered RCTs may provide further direction regarding the efficacy of preoperative alphablockers for URS of ureteral stones.

Recommendation: Preoperative alpha-blockers may improve intraoperative and postoperative outcomes for patients undergoing URS. However, the optimal duration of preoperative alpha-blocker therapy is still uncertain (level 1 , moderate recommendation).

\section{Postoperative imaging}

The goal of postoperative imaging is to assess for residual stone burden and screen for ongoing obstruction. Residual stone fragments may lead to additional stone-related episodes and surgical intervention. ${ }^{107,108}$ Some authors have concluded that in the setting of uncomplicated URS, routine postoperative upper tract imaging is not necessary. ${ }^{109}$ Instead, they have recommended postoperative imaging indications include chronic stone impaction, significant ureteral trauma, prior renal impairment, endoscopic evidence of stricture, and postoperative pain or fever. However, silent obstruction, described as asymptomatic, persistent, postoperative obstructive hydronephrosis, has been shown to occur at a rate of $1.9-10 \%$ following URS, highlighting the importance of routine postoperative imaging. ${ }^{109-111}$ The mean interval from URS to possible development of ureteral stricture is estimated to be 13 months. ${ }^{112}$ While NCCT is the best modality for identifying both residual fragments and postoperative obstruction, the effective dosage of radiation and the cost of this modality have prevented its routine use post-URS. Rather, a combination of US and KUB X-ray are typically used to detect obstruction and stone-free status.

Recommendation: An US \pm KUB X-ray is recommended following URS for ureteral stones (level 4, strong recommendation). In complicated cases, further imaging with NCCT can be performed. 


\section{Ureteral access sheaths}

Ureteral access sheaths (UAS) can offer numerous advantages during URS. They allow for rapid and multiple reentries into the upper tract, potentially reducing damage to the ureteroscope. UAS can also enhance visibility, decrease intrarenal pressure, and allow for drainage and elimination of dust and stone fragments. ${ }^{113}$ The proper selection of UAS size is crucial to balancing URS outcomes. Excessive force should never be applied when using UAS. Most of the literature on UAS use during URS is related to renal stones.

In a prospective cohort analysis of 2239 patients, no significant difference in SFR was seen whether a UAS was or was not used during flexible URS $(75.3 \%$ vs. $50.4 \%$, $\mathrm{p}=0.604) .{ }^{114}$ However, in a subgroup analysis of stones $\geq 10$ $\mathrm{mm}, \mathrm{SFRs}$ were significantly higher in the UAS group $(84.9 \%$ vs. $81.5 \%, p<0.01)$. One systematic review revealed no significant difference in operative times, SFRs, or intraoperative complications with UAS use. ${ }^{115}$ A critical drawback of these systematic reviews is that a substantial number of studies did not use NCCT to determine true SFR and as a result, the impact of UAS use on SFR after URS remains unclear.

In a study of 2239 patients treated with flexible URS, no significant difference in ureteral injuries was reported in patients treated with UAS in comparison to those without UAS. ${ }^{114}$ Grades of ureteral injuries related to UAS were reported as low-grade injuries involving the mucosa in almost half of patients and high-grade lesions involved smooth muscle layer in $15 \%$ of patients. ${ }^{116}$ Importantly, endoscopically detected high-grade ureteral lesions following UAS insertion do not appear to result in an increased rate of stricture. ${ }^{117}$

Recommendation: Current evidence suggests UAS use for ureteral stones has no significant impact on SFR nor on intraoperative complications (level 2, moderate recommendation), but may improve visualization, reduce intra-renal pressures, and facilitate fragment removal (level 4, strong recommendation).

\section{Stenting}

Ureteral stent placement prior to elective URS can facilitate UAS and ureteroscope insertion. In a recent prospective study of rigid and flexible ureteroscopes, the ureter was inaccessible in $8 \%$ of cases, necessitating the placement of a ureteral stent and delayed definitive treatment. ${ }^{118}$ Some studies have demonstrated no clear advantage in SFR nor complication rate with routine preoperative stenting, ${ }^{119,120}$ while others have shown routine pre-URS stenting was associated with a higher SFR for larger stones. ${ }^{121-123}$

The impact of post-URS stenting on SFR is not clear and meta-analyses have shown conflicting results. One recent meta-analysis found that stenting did not improve SFR nor reduce late postoperative complications after routine URS. ${ }^{124}$ Conversely, in another meta-analysis of 22 RCTs, the SFR was significantly better in the stented group $(95 \% \mathrm{CI} 0.34-$ $0.89 ; \mathrm{p}=0.01) .{ }^{101}$ In terms of the impact on stricture rate, a meta-analysis of 14 trials and 1652 patients demonstrated that post-URS stenting likely does not reduce stricture rates at 90 days ( $\mathrm{RR} 0.58, \mathrm{Cl} 0.23-1.47$ ). ${ }^{125}$ Conversely, use of a stent has been shown to reduce unplanned medical visits post-URS. ${ }^{125-127}$ Following UAS use, routine ureteral stenting seems to be beneficial in reducing pain and unplanned medical visits. ${ }^{128,129}$

Nonetheless, there are scenarios where routine post-URS stent placement is advisable: suspected ureteric injury or stricture, solitary kidney, and patient with renal impairment.

The evidence is not clear on whether use of a stent postURS impacts opioid use, ${ }^{125,130}$ but urinary symptoms have been demonstrated to be significantly worse with stent use. ${ }^{101,124,126,131}$ Studies have demonstrated beneficial effects of various medications (e.g., alpha-blockers, anticholinergics, B-agonists) to ameliorate stent-related urinary symptoms. ${ }^{132,133}$

There is no consensus regarding the optimum duration of postoperative stenting. In an animal model, there were no histological ischemic changes in the ureteral wall 72 hours post-UAS insertion, suggesting that three days may be sufficient. ${ }^{134}$ On the other hand, Paul et al compared ureteral stent dwell times of three vs. seven days and found that removal at three days was linked to a higher probability of obstruction-related adverse events $(23 \%$ vs. $3 \%){ }^{135}$

Recommendation: Routine pre-URS stenting is not necessary but may facilitate UAS insertion and improve SFRs in patients with larger stones (level 2, weak recommendation). Routine stenting after uncomplicated URS is likely unnecessary (level 2, strong recommendation) but stent placement after UAS use is warranted (level 3, weak recommendation). Stent-related symptoms following URS may be ameliorated with alpha-blocker and/or anticholinergic medications (level 2, moderate recommendation). If access to the ureteral stone is complicated or impossible, placement of a stent and repeat URS is the safest option (level 5, strong recommendation).

\section{Comparing treatment outcomes - SWL vs. URS}

\section{Stone-free rate}

Previously published literature comparing SWL vs. URS for ureteric calculi, which focused largely on efficacy and safety, guided the development of the 2015 CUA guideline recommendations. Since then, several other studies have been published, including some important data on cost-effectiveness 
and patient-reported outcomes. Due to the significant variation and heterogeneity of the techniques used to perform SWL and URS, it is difficult to make clear recommendations based on published literature.

For upper ureteric stones, a randomized trial of semirigid URS compared to $\mathrm{SWL}$ for stones $<2 \mathrm{~cm}$ showed similar SFR $(86.6 \%$ vs. $82.2 \%)$ at three months. ${ }^{136}$ Those undergoing SWL had significantly higher re-treatment rates but after re-treatment, the need for subsequent auxiliary treatments was similar $(21.1 \%$ vs. $17.7 \%, p<0.5)$. When the groups were substratified by stone size, URS produced a higher SFR for stones $1-2 \mathrm{~cm}(85.4 \%$ vs. $78.4 \%)$, though this was not statistically significant. Complication rates were also statistically similar $(11.1 \%$ vs. $6.6 \%, p=0.21)$.

When dealing with distal ureteral stones, URS has traditionally been thought to produce superior results to SWL. However, several studies have demonstrated similar SFR between SWL and URS, with the caveat that SWL often required more than one treatment to achieve that same SFR. ${ }^{137-140}$ A systematic review published in 2017 found that there was a better SFR with URS at four weeks, but this was comparable between groups at three months. ${ }^{141}$ There were fewer re-treatments with URS, but higher complication rates. In terms of radiation doses to patients, one study showed equal amounts of radiation used for ureteral stones whether treating with URS or SWL. ${ }^{142}$

Costs can vary from region to region for each modality; an American study found that for ureteral stones $\leq 1.5 \mathrm{~cm}$, the equivalency point for cost efficacy was when the SFR for SWL was $<60-64 \%$ or if the chance of URS success was $>57-76 \% .{ }^{143}$ For these situations, URS was found to be more cost-effective in an American system. A British cost-efficacy study was undertaken according to their National Institute for Health and Care Excellence (NICE) guidelines ${ }^{144}$ and they concluded that for ureteral stones $<1 \mathrm{~cm}$, URS would be more costly even if SWL was only $40 \%$ efficacious.

Recommendation: SWL produces similar SFR to URS for ureteral stones, albeit with a higher retreatment rate and lower complication rate (level 1 , strong recommendation). While local/regional cost models need to be considered, SWL may be a more cost-effective option for ureteric stones (level 4, weak recommendation).

\section{Patient-reported outcomes}

Ureteral stones can have a significant impact on the healthrelated quality of life (HRQOL) of patients. ${ }^{145-149}$ Both SWL and URS have been found to have significant impacts on kidney stone patients' quality of life.

Overall, patients with ureteral stones are satisfied with their treatment choice approximately $50 \%$ of the time and there is no difference in treatment satisfaction correlated to the selected modality (SWL vs. URS). ${ }^{150-152}$ However, in one study specifically examining distal ureteric calculi, it was determined that more patients were satisfied with URS $(n=113 ; 94.2 \%)$ compared to SWL $(n=74 ; 80.4 \%)$ $(\mathrm{p}=0.002) .{ }^{153}$

Regarding HRQOL, the main HRQOL outcomes affected by SWL and URS are the physical functioning, social functioning, and pain domains on the 36-item Short Form Health Survey (SF-36). ${ }^{154,155}$ A study comparing the HRQOL between patients who received SWL to those who received URS using the SF-36, found that patients who received URS scored worse than those who received SWL due in part to the higher analgesic requirements and longer hospital stay after URS compared to SWL, which was mainly attributed to the use of a ureteral stent. ${ }^{156}$ Interestingly, the improved HRQOL for SWL over URS extended beyond the short-term and persisted at six months of followup, despite the higher SFR with URS. In contrast, a study compared the impact of URS vs. SWL on the HRQOL of patients with proximal ureteral stones and found that although there was no difference in change in HRQOL for patients with stones $<10 \mathrm{~mm}$, patients who underwent SWL for proximal ureteral stones $>10 \mathrm{~mm}$ scored significantly lower on their SF-36. ${ }^{157}$ Finally, a systematic review examined how ureteric calculi influence HRQOL and patient treatment preference. ${ }^{158} \mathrm{~A}$ number of studies were reviewed, however, overall URS and SWL were both found to significantly impact SF-36 results similarly.

Recommendation: Overall, there is similar patient satisfaction between SWL and URS for the treatment of ureteric calculi, but SWL has been found to have slightly better HRQOL outcomes, due primarily to the avoidance of a ureteral stent (level 2, moderate recommendation).

\section{Special clinical considerations}

\section{Anticoagulation}

Some studies have shown up to a 20- to 40-fold increased risk of peri-renal hematomas and hemorrhagic complications among patients with uncorrected coagulopathies undergoing SWL when compared with patients with a normal bleeding profile. ${ }^{159-162}$ As such, in consultation with a hematologist or a cardiologist, bleeding coagulopathies need to be corrected and anticoagulation therapy appropriately witheld around the time of SWL. ${ }^{163}$ Patients with an increased risk of thromboembolic disease should be managed by bridging therapy while oral anticoagulation is held. ${ }^{164}$

A retrospective study of 434 patients on acetylsalicylic acid (ASA) or low-molecular-weight heparin (LMWH) undergoing SWL for renal and proximal ureteric stones demonstrated that the continued use of ASA and a therapeutic (but 
not prophylactic) dose of $\mathrm{LMWH}$ were independent predictors of renal hematoma, as determined by ultrasound one day post-SWL. ${ }^{165}$ A systematic review performed in 2014 found sparse and poor-quality evidence with respect to the safety of SWL while on antiplatelet or anticoagulant medications, but one of the authors' conclusions included careful consideration of SWL among patients on low-dose ASA. ${ }^{166}$

Recent advances in URS technology have made it possible for patients with coagulopathies to safely undergo URS and laser lithotripsy while anticoagulated. ${ }^{160,167-170}$ However, this is associated with lower SFRs and increased risk of postoperative gross hematuria necessitating admission and bladder irrigation. ${ }^{161,171}$ Therefore, risks and benefits of withholding anticoagulation or proceeding with URS while anticoagulated should be discussed with the patient and his/her cardiologist or hematologist.

In terms of using a UAS during URS for patients on anticoagulants, studies have demonstrated no increased risk of hemorrhagic complications. ${ }^{116,169}$

Recommendations: SWL and antegrade URS are contraindicated in patients with uncorrected coagulopathies. When the risk of holding antiplatelet or anticoagulants outweigh the benefits, proceeding with URS while a patient is anticoagulated is an acceptable option (level 2, moderate recommendation).

\section{Antegrade management of ureteral stones}

Antegrade URS can be considered a treatment option in the following situations: 1) patients with a urinary diversion in whom SWL or retrograde access is not feasible; 2 ) in select cases with a large, impacted proximal ureteral stones; 3 ) when performed in conjunction with renal stone removal; 4) in select cases following failure of a retrograde URS attempt fora large, impacted proximal ureteral stone; ${ }^{172}$ and 5) when the ureteral stone is in a transplant kidney. ${ }^{173}$

Dealing with stones in patients with urinary diversions represents a challenge to most urologists. The established anatomical changes in these patients necessitate accurate preoperative assessment by NCCT. ${ }^{174}$ If SWL is not an option or the patient's stone doesn't respond to SWL, one of the most important factors to consider is whether retrograde access to the ureter is possible. If the ureter is accessible through a retrograde approach (e.g., through an ileal conduit), flexible retrograde URS may be a good option, as antegrade URS in these patients is associated with higher rates of postoperative fever or sepsis $(8 \% \mathrm{vs.} 0 \%, \mathrm{p}<0.05)$ and higher rates of second-look nephroscopy (36\%vs. $16 \%$, p<0.05) compared to those with normal anatomy. ${ }^{175}$

For large (>15 mm), impacted, proximal ureteral stones, the SFR with antegrade URS ranges from $98.5-100 \%$, with a low risk for complications. ${ }^{172,176-180}$ However, as would be expected, the antegrade approach is associated with longer fluoroscopy time, longer procedural time, and longer hospital stay. ${ }^{181}$

Recommendations: Percutaneous antegrade URS should be considered in the treatment of stones in patients with urinary diversion and select large, impacted, proximal ureteral stones, especially when prior retrograde URS has failed (level 4, strong recommendation).

\section{Ureteral stones in children}

Pediatric urolithiasis has become increasingly common in the last two decades, with the incidence increasing approximately $4-10 \%$ annually. ${ }^{182,183}$

\section{Diagnostic imaging}

Due to concerns regarding radiation exposure in children, US is used more commonly than in adults as the first-line diagnostic modality when renal colic is suspected. ${ }^{184-186}$ However, similar to adults, there are sensitivity issues with US, in particular for mid-ureteral calculi. ${ }^{187}$ The addition of conventional radiography (KUB X-ray) can improve diagnostic accuracy, ${ }^{188,189}$ but as in adults, NCCT has the highest sensitivity and specificity. ${ }^{185,186,190}$ The use of ultra-low-dose NCCT can mitigate radiation exposure to levels similar to KUB X-ray, while maintaining diagnostic performance. ${ }^{191,192}$

\section{Management}

The optimal management of ureteral stones in children is dependent on patient and stone factors, similar to adults, but the anatomic spectrum of pediatric patients, and the subsequent management, varies much more widely. ${ }^{193}$ Unless there is an indication to intervene acutely, a trial of passage of at least two weeks is the first-line management in children with urolithiasis $<5 \mathrm{~mm}$. ${ }^{105,185,193-196}$ If urinary drainage is urgently required, ureteral stent insertion is preferred in children due to decreased complications compared to percutaneous decompression. Evidence suggests MET in children may be effective and safe. ${ }^{193,194,197}$

There is a paucity of high-level evidence in the literature regarding the optimal management algorithm for pediatric patients requiring surgical intervention for ureteric stones. ${ }^{193,198}$ In children with mid to distal urolithiasis, URS has been consistently shown to be superior to SWL and thus is recommended as first-line management. ${ }^{105,185,199-201}$

For children with proximal ureteral stones, the overall SFRs between SWL and URS have been shown to be similar, ${ }^{198}$ so both SWL and URS may be considered first-line options. The usual considerations regarding the suitability of SWL must be considered. In children with large stone burdens, repeated procedures may be required or discussions involving more invasive options (percutaneous ante- 
grade URS or open/laparoscopic/robotic procedures) may be undertaken. ${ }^{105,185}$

Retrograde access for children who have undergone a Cohen cross-trigonal ureteral re-implantation can be uniquely challenging but is not a contraindication for URS. ${ }^{202}$

\section{Complications}

The complication and re-treatment rates for pediatric SWL are similar to those of adults. ${ }^{198,199}$ However, unlike the adult population, the complication rates for pediatric URS varies widely (3.7-20.5\%). ${ }^{188,198,203,204}$ In particular, overall reported rates of ureteral injury $(2.1-2.8 \%)$, ureteric stricture $(0.2-1.0 \%)$, and ureteral avulsion $(0.4 \%)$ are higher among the pediatric population. ${ }^{200,203}$ The complications associated with pediatric URS are more strongly linked with age/size of the child and equipment size. ${ }^{203,205}$ To minimize ureteric complications, it is recommended that ureteroscopes $<8$ French be used on pediatric patients, ${ }^{199,200,204,205}$ and that mini 4.5 French ureteroscopes be used for children $<3$ years old. ${ }^{203}$

\section{Stenting}

Data does not support routine pre-stenting prior to URS in children. ${ }^{105}$ However, failed retrograde access is more common in children (30-70\%) than adults. ${ }^{196,206}$ In these situations, pre-stenting and repeat URS after passive dilation may be preferable to active dilation with catheters, balloon dilators, and sheaths due to risk of significant ureteric trauma. This is especially true in younger children. ${ }^{188}$

Postoperative stenting should be performed at the discretion of the attending physician, with similar indications as in adults. ${ }^{185,205}$

\section{Followup}

There are no clear differences between pediatric and adult followup post-surgical intervention for urolithiasis. In most series, postoperative ureteral stents are removed within 1-2 weeks under a second general anesthesia. Alternative options include magnetic and tethered stents.

Postoperatively, children should be followed with an US and KUB X-ray 4-6 weeks after the procedure. ${ }^{200,205,207,208}$ After their first episode of urolithiasis, the overall recurrence rates in the pediatric population ranges from $19-50 \%$ over a followup of 2-3 years. ${ }^{195,209,210}$ However, there is currently no high-level evidence dictating a specific surveillance schedule. As such, it is recommended that this mirror that of the adult population.

Recommendation: Ultrasound is the first-line diagnostic modality used in children with suspected ureteral stones. This may be coupled with a KUB X-ray to increase accuracy. Low-dose NCCT may be used in certain situations (level 3 , strong recommendation). A trial of passage with/without
MET is recommended for children with smaller $(<5 \mathrm{~mm})$ stones (level 2, strong recommendation). SWL is a safe and effective option for ureteral stones in children (level 2, strong recommendation). If ureteral dilation is required, passive dilation is preferred (level 4 , moderate recommendation). It is recommended that ureteroscopes $<\mathbf{8}$ French be used for URS in children (level 4, moderate recommendation).

\section{Pregnancy}

No level 1 evidence exists regarding the treatment of ureteral stones during pregnancy. Retrospective case series provide some guidance on how to manage this situation.

\section{Diagnostic imaging}

The first diagnostic test in suspected nephrolithiasis during pregnancy should be US (abdominal \pm transvaginal) due to the lack of radiation. However, if US is non-diagnostic, magnetic resonance imaging (MRI) can be considered in the first trimester. ${ }^{211,212}$ If available, a protocol involving magnetic resonance urography (MRU) with a T2-weighted half Fourier single-shot turbo spin-echo (HASTE) is preferred due to improved accuracy. ${ }^{213}$ Ultra-low/low-dose NCCT may be considered as additional options in the second and third trimesters. ${ }^{186,214,215}$

\section{Management}

Most ureteral stones will pass spontaneously and the first option in management is conservative therapy, including hydration and analgesia. ${ }^{216}$ NSAIDs should be avoided in pregnancy due to known fetal risks. ${ }^{217}$ Data suggests MET with alpha-blockers is relatively safe in this patient population, however, efficacy is currently not well-established. ${ }^{218,219}$ It should be noted that these medications are category B-rated and should be used with caution, as an off-label adjunct. ${ }^{105}$

Immediate causes for intervention are the same as those in non-pregnant situations, but also include induction of premature labor (contractions, fetal distress). ${ }^{220}$ The immediate methods of intervention in these situations are NT or ureteral stent insertion. Although safe, the evidence for NT placement are comprised of small, low-level studies. ${ }^{221-223}$ In pregnancy, ureteral stents and NTs are at risk for accelerated encrustation, thereby requiring changes every 4-6 weeks. ${ }^{224,225}$

Failing conservative management, URS using laser lithotripsy has been shown to be feasible and safe..$^{226}$ In fact, if ultrasound imaging is non-diagnostic and low-dose NCCT or MRI is unavailable, URS can also be used for both diagnostic and therapeutic purposes. ${ }^{227,228} \mathrm{~A}$ number of studies have demonstrated that URS is a viable technique to treat stones in pregnancy. 227,229-233 Postoperative stenting following URS in this situation is recommended in an attempt to reduce postoperative complications. ${ }^{227,234}$ With respect to safety of 
the pregnancy, traditional teaching was that URS should be undertaken during the second trimester, ${ }^{220,235}$ but more recent literature suggests there is no evidence to support a "safest" trimester. ${ }^{221}$

With regards to intraoperative imaging, if URS or ureteral stent insertion is undertaken, then a lead apron or shield should be put between the X-ray fluoroscopy source and the fetus to shield it from radiation. ${ }^{236}$ Alternatively, URS or ureteral stent insertion can be performed under US guidance alone, avoiding radiation exposure. Continuous fetal monitoring has been advocated during these interventions, ${ }^{212,220}$ although may not always be necessary.

Pregnancy is a contraindication to SWL, and although there have been reports of the inadvertent treatment of pregnant patients with SWL with no adverse sequelae to the fetus, ${ }^{237}$ it should be avoided. Similarly, antegrade URS should likely be delayed until after birth, as the procedure may require prolonged anesthesia and radiation exposure. However, some case series of safe PCNL during pregnancy have been published. ${ }^{238}$

Recommendation: First-line diagnostic testing for stones in pregnancy is US, but low-dose NCCT or MRI (without gadolinium in the first trimester) can also be used (level 3 , strong recommendation). Obstructing ureteral stones in pregnancy can be managed conservatively in the absence of suspected or confirmed urinary infection (level 3, moderate recommendation). In pregnant patients presenting with signs of sepsis, antibiotics and urinary decompression via a NT or ureteral stent are of primary importance; consultation with the obstetrics team is recommended. URS with laser lithotripsy is safe in pregnancy; however, SWL is contraindicated (level 2, strong recommendation).

Competing interests: Dr. Lee has received a speaker honorarium from Baxter. Dr. Bhojani has reviewed new products for Boston Scientific and participated in WATER 2, an Aquablation multiinstitutional clinical trial supported by Procept. Dr. Chew has been a consultant for Auris Robotics, Bard Medical, Boston Scientific, and Olympus; has been a lecturer for Boston Scientific, Coloplast, Cook Medical, and Olympus; received a study grant from Boston Scientific; received a fellowship salary from Cook Medical; and participated in clinical trials supported by Boston Scientific and Cook Medical. Dr. Elmansy has received payment from Boston Scientific, Clarion Medical Technologies/ AccuTech Medical Technologies, and Janssen; and received speaker honoraria and a travel grant from Lumenis. Dr. Pace has received support for a fellowship and annual lectureship from Cook Urological. The remaining authors report no competing personal or financial interests related to this work.

Acknowledgement: The authors would like to thank Simon Czajkowski, MSc (Phys), MBE, for his assistance in collating and synthesizing the many references in this document. They would also like to thank Robin Parker, MLIS, PhD(c), for her assistance in conducting the literature search for the section on SWL.

\section{References}

1. Scales CD, Smith AC, Hanley JM, et al. Prevalence of kidney stones in the United States. Eur Urol 2012;62:160-5. https://doi.org/10.1016/i.eururo.2012.03.052

2. Sorokin I, Mamoulakis C, Miyazawa K, et al. Epidemiology of stone disease across the world. World J Urol 2017;35:1301-20. https://doi.org/10.1007/s00345-017-2008-6

3. Raheem OA, Khandwala YS, Sur RL, et al. Burden of urolithiasis: Trends in prevalence, treatments, and costs. Eur Urol Focus 2017;3:18-26. https://doi.org/10.1016/i.euf.2017.04.001

4. Innes G, McRae A, Grafstein E, et al. Variability of renal colic management and outcomes in two Canadian cities. Can J Emerg Med 2018;20:702-12. https://doi.org/10.1017/cem.2018.31

5. Dauw CA, Kaufman SR, Hollenbeck BK, et al. Expulsive therapy vs. early endoscopic stone removal in patients with acute renal colic: A comparison of indirect costs. J Urol 2014;191:673-7. https://doi. org/10.1016/i.juro.2013.09.028

6. Ordon M, Andonian S, Blew B, et al. CUA guideline: Management of ureteral calculi. J Can Urol Assoc 2015;9:E837-51. https://doi.org/10.5489/cuai.3483

7. Howick J, Chalmers I, Glasziou P, et al. The Oxford Levels of Evidence 2. Published 2011. Available at: https://www.cebm.ox.ac.uk/resources/levels-of-evidence/ocebm-levels-of-evidence. Accessed August 21, 2021

8. Skolarikos $A$, Laguna $M P$, Alivizatos $G$, et al. The role for active monitoring in urinary stones: A systematic review. J Endourol 2010;24:923-30. https://doi.org/10.1089/end.2009.0670

9. Dellabella M, Milanese G, Muzzonigro G. Randomized trial of the efficacy of tamsulosin, nifedipine, and phloroglucinol in medical expulsive therapy for distal ureteral calculi. J Urol 2005;174:167-72. https://doi.org/10.1097/01.ju.0000161600.54732.86

10. Ye Z, Yang H, Li H, et al. A multicentre, prospective, randomized trial: Comparative efficacy of tamsulosin and nifedipine in medical expulsive therapy for distal ureteric stones with renal colic. BJU Int 2011;108:276-9. https://doi.org/10.1111/i.1464-410X.2010.09801.x

11. Pickard R, Starr K, Maclennan G, et al. Medical expulsive therapy in adults with ureteric colic: A multicenter, randomized, placebo-controlled trial. Lancet 2015;386:341-9. https://doi.org/10.1016/ S0140-6736(15)60933-3

12. Borofsky MS, Walter $D$, Shah 0 , et al. Surgical decompression is associated with decreased mortality in patients with sepsis and ureteral calculi. J Urol 2013;189:946-51. https://doi.org/10.1016/i. juro.2012.09.088

13. Haas CR, Smigelski M, Sebesta EM, et al. Implementation of a hospital-wide protocol reduces time to decompression and length of stay in patients with stone-related obstructive pyelonephritis with sepsis. $J$ Endourol 2021;35:77-83. https://doi.org/10.1089/end.2020.0626

14. Varda B, Sood A, Krishna N, et al. National rates and risk factors for stent failure after successful insertion in patients with obstructed, infected upper tract stones. Can Urol Assoc J 2015;9:E164-71. https://doi.org/10.5489/cuai.2456

15. Mokhmali $\mathrm{H}$, Braun PM, Martinez Portillo $\mathrm{FJ}$, et al. Percutaneous nephrostomy vs. ureteral stents for diversion of hydronephrosis caused by stones: A prospective, randomized clinical trial. J Urol 2001;165:108892. https://doi.org/10.1016/50022-5347(05)66434-8

16. Pearle MS, Pierce HL, Miller GL, et al. Optimal method of urgent decompression of the collecting system for obstruction and infection due to ureteral calculi. J Urol 1998;160:1260-4. https://doi.org/10.1016/ S0022-5347(01)62511-4

17. Christoph F, Weikert $S$, Müller M, et al. How septic is urosepsis? Clinical course of infected hydronephrosis and therapeutic strategies. World J Urol 2005;23:243-7. https://doi.org/10.1007/s00345005-0002-x

18. Ramsey S, Robertson A, Ablett MJ, et al. Evidence-based drainage of infected hydronephrosis secondary to ureteric calculi. J Endourol 2010;24:185-9. https://doi.org/10.1089/end.2009.0361

19. Yoshimura $\mathrm{K}$, Utsunomiya $\mathrm{N}$, Ichioka $\mathrm{K}$, et al. Emergency drainage for urosepsis associated with upper urinary tract calculi. J Urol 2005;173:458-62. htrps://doi.org/10.1097/01.ju.0000150512.40102.bb

20. Shi YF, Ju WL, Zhu YP, et al. The impact of ureteral stent indwelling time on the treatment of acute infection caused by ureteral calculi. Urolithiasis 2017;45:579-83. https://doi.org/10.1007/s00240-017-0964-3

21. Singer $M$, Deutschman $C S$, Seymour $C$, et al. The third international consensus definitions for sepsis and septic shock (sepsis-3). JAMA 2016;315:801-10. https://doi.org/10.1001/jama.2016.0287

22. Jennings $C A$, Khan $Z$, Sidhu $P$, et al. Management and outcome of obstructive ureteral stones in the emergency department: Emphasis on urine tests and antibiotics usage. Am J Emerg Med 2019;37:1855-9. https://doi.org/10.1016/i.ajem.2018.12.046

23. Kim HY, Choe HS, Lee DS, et al. Transient renal impairment in the absence of pre-existing chronic kidney disease in patients with unilateral ureteric stone impaction. Urolithiasis 2017;45:249-54. https://doi.org/10.1007/s00240-016-0904-7 
24. Guercio S, Ambu A, Mangione F, et al. Randomized prospective trial comparing immediate versus delayed ureteroscopy for patients with ureteral calculi and normal renal function who present to the emergency department. J Endourol 2011;25:1137-41. https://doi.org/10.1089/end.2010.0554

25. Kumar A, Mohanty NK, Jain M, et al. A prospective randomized comparison between early $(<48$ hours of onset of colicky pain) versus delayed shockwave lithotripsy for symptomatic upper ureteral calculi: A single-center experience. J Endourol 2010;24:2059-66. https://doi.org/10.1089/end.2010.0066

26. Uguz S, Senkul T, Soydan H, et al. Immediate or delayed SWL in ureteric stones: A prospective and randomized study. Urol Res 2012;40:739-44. https://doi.org/10.1007/s00240-012-0490-2

27. Westphalen AC, Hsia RY, Maselli JH, et al. Radiological imaging of patients with suspected urinary tract stones: National trends, diagnoses, and predictors. Acad Emerg Med 2011;18:699-707. https://doi.org/10.1111/i.1553-2712.2011.01103.x

28. Chang HC, Raskolnikov D, Dai JC, et al. national imaging trends in nephrolithiasis - does renal ultrasound in the emergency department pave the way for computerized tomography? Urol Pract 2021;8:82-7. https://doi.org/10.1097/UPJ.0000000000000148

29. Innes GD, Scheuermeyer FX, Law MR, et al. Sex-related differences in emergency department renal colic management: Females have fewer computed tomography scans but similar outcomes. Acad Emerg Med 2016;23:1153-60. https://doi.org/10.1111/acem.13041

30. Schoenfeld EM, Pekow PS, Shieh MS, et al. The diagnosis and management of patients with renal colic across a sample of us hospitals: High CT utilization despite low rates of admission and inpatient urologic intervention. PLoS One 2017;12:e0169160. https://doi.org/10.1371/journal.pone.0169160

31. Smith-Bindman R, Aubin C, Bailitz J, et al. Ultrasonography versus computed tomography for suspected nephrolithiasis. N Engl J Med 2014;371:1100-10. https://doi.org/10.1056/NEJMoa1404446

32. Ripollés $T$, Agramunt $M$, Errando J, et al. Suspected ureteral colic: Plain film and sonography vs. unenhanced helical CT: A prospective study in 66 patients. Eur Radiol 2004;14:129-36. https://doi.org/10.1007/ s00330-003-1924-6

33. Foell K, Ordon $M$, Ghiculete $D$, et al. Does baseline radiography of the kidneys, ureters, and bladder help facilitate stone management in patients presenting to the emergency department with renal colic? J Endourol 2013;27:1425-30. htrps://doi.org/10.1089/end.2013.0183

34. Gervaise A, Naulet $P$, Beuret $F$, et al. Low-dose CT with automatic tube current modulation, adaptive statistical iterative reconstruction, and low tube voltage for the diagnosis of renal colic: Impact of body mass index. Am J Roentgenol 2014;202:553-60. https://doi.org/10.2214/AJR.13.11350

35. Mclaughlin PD, Mallinson P, Lourenco P, et al. Dual-energy computed tomography: Advantages in the acute setting. Radiol Clin North Am 2015;53:619-38. hitps://doi.org/10.1016/i.rcl.2015.02.016

36. Sur RL, Shore N, L'Esperance J, et al. Silodosin to facilitate passage of ureteral stones: A multi-institutional, randomized, double-blinded, placebo-controlled trial. Eur Urol 2015;67:959-64. https://doi. org/10.1016/j.eururo.2014.10.049

37. Furyk JS, Chu K, Banks C, et al. Distal ureteric stones and tamsulosin: A double-blind, placebo-controlled, randomized, multicenter trial. Ann Emerg Med 2016;67:86-95.e2. https://doi.org/10.1016/j.annemergmed.2015.06.001

38. Cui Y, Chen J, Zeng F, et al. Tamsulosin as a medical expulsive therapy for ureteral stones: A systematic review and meta-analysis of randomized controlled trials. J Urol 2019;201:950-5. https://doi.org/10.1097/JU.0000000000000029

39. Hollingsworth JM, Canales BK, Rogers MAM, et al. Alpha blockers for treatment of ureteric stones: systematic review and meta-analysis. BMJ 2016;355:i6112. https://doi.org/10.1136/bmi.i6112

40. Amer T, Osman B, Johnstone A, et al. Medical expulsive therapy for ureteric stones: Analyzing the evidence from systematic reviews and meta-analysis of powered double-blinded randomized controlled trials. Arab J Urol 2017;15:83-93. https://doi.org/10.1016/i.aju.2017.03.005

41. Ye Z, Zeng G, Yang $\mathrm{H}$, et al. Efficacy and safety of tamsulosin in medical expulsive therapy for distal ureteral stones with renal colic: A multicenter, randomized, double-blind, placebo-controlled trial [figure presented]. Eur Urol 2018;73:385-91. https://doi.org/10.1016/i.eururo.2017.10.033

42. Türk C, Knoll T, Seitz C, et al. Medical expulsive therapy for ureterolithiasis: The EAU recommendations in 2016. Eur Urol 2017;71:504-7. htrps://doi.org/10.1016/i.eururo.2016.07.024

43. Campschroer T, Zhu X, Vernooij RWM, et al. Alpha-blockers as medical expulsive therapy for ureteral stones. Cochrane Database Syst Rev 2018;4:CD008509. https://doi.org/10.1002/14651858. CD008509.pub3

44. Rui P, Santo L, Ashman JJ. Trends in opioids prescribed at discharge from emergency departments among adults: United States, 2006-2017. Natl Heal Stat Rep 2020;135:1-12. https://pubmed.ncbi.nlm. nih.gov/32510308/

45. Pathan SA, Mitra B, Straney LD, et al. Delivering safe and effective analgesia for management of renal colic in the emergency department: A double-blind, multigroup, randomized controlled trial. Lancet 2016;387:1999-2007. https://doi.org/10.1016/S0140-6736(16)00652-8

46. Minhaj FS, Hoang-Nguyen M, Tenney A, et al. Evaluation of opioid requirements in the management of renal colic after guideline implementation in the emergency department. Am J Emerg Med 2020;38:2564-9. https://doi.org/10.1016/i.ajem.2019.12.042
47. Leapman $M S$, Derycke $E$, Skanderson $M$, et al. Variation in national opioid prescribing patterns following surgery for kidney stones. Pain Med (United States) 2018;19:S12-8. https://doi.org/10.1093/pm/ pnyl25

48. Taenzer P, Melzack R, Jeans ME. Influence of psychological factors on postoperative pain, mood, and analgesic requirements. Pain 1986;24:331-42. https://doi.org/10.1016/0304-3959(86)90119-3

49. Worster AS, Bhanich Supapol W. Fluids and diuretics for acute ureteric colic. Cochrane Database Syst Rev 2012:CD004926. hitps://doi.org/10.1002/14651858.CD004926.pub3

50. Meltzer AC, Burrows PK, Kirkali Z, et al. Accuracy of patient reported stone passage for patients with acute renal colic treated in the emergency department. Urology 2020;136:70-4. https://doi.org/10.1016/i. urology.2019.10.010

51. McLarty R, Assmus M, Senthilselvan A, et al. Patient reported outcomes predicting spontaneous stone passage may not have acceptable accuracy. J Urol 2020;204:524-30. https://doi.org/10.1097/ JU.0000000000001030

52. Cheng RZ, Shkolyar E, Chang TC, et al. Ultra-low-dose CT: An effective followup imaging modality for ureterolithiasis. J Endourol 2020;34:139-44. https://doi.org/10.1089/end.2019.0574

53. Horne KL, Packington R, Monaghan J, et al. Three-year outcomes after acute kidney injury: Results of a prospective parallel group cohort study. BMJ Open 2017;7:e015316. https://doi.org/10.1136/ bmiopen-2016-015316

54. Meldrum KK. Pathophysiology of urinary tract obstruction. Campbell-Walsh Urology 2015:1101-1102.

55. Saw KC, Lingemann JE. Lesson 20: Management of calyceal stones. 1999:154-9.

56. Gupta NP, Ansari MS, Kesarvani P, et al. Role of computed tomography with no contrast medium enhancement in predicting the outcome of extracorporeal shockwave lithotripsy for urinary calculi. BJU Int 2005;95:1285-8. https://doi.org/10.1111/j.1464-410X.2005.05520.x

57. Joseph P, Mandal AK, Singh SK, et al. Computerized tomography attenuation value of renal calculus: can it predict successful fragmentation of the calculus by extracorporeal shockwave lithotripsy? A preliminary study. J Urol 2002;167:1968-71. hitps://doi.org/10.1016/S0022-5347(05)65064-1

58. Abdelhamid M, Mosharafa AA, Ibrahim H, et al. A prospective evaluation of high-resolution CT parameters in predicting extracorporeal shockwave lithotripsy success for upper urinary tract calculi. J Endourol 2016;30:1227-32. https://doi.org/10.1089/end.2016.0364

59. El-Nahas AR, El-Assmy AM, Mansour 0 , et al. A prospective multivariate analysis of factors predicting stone disintegration by extracorporeal shockwave lithotripsy: The value of high-resolution non-contrast computed tomography. Eur Urol 2007;51:1688-94. htrps://doi.org/10.1016/j.eururo.2006.11.048

60. Ouzaid I, Al-Qahtani S, Dominique S, et al. A 970 Hounsfield units (HU) threshold of kidney stone density on non-contrast computed tomography (NCCT) improves patients' selection for extracorporeal shockwave lithotripsy (ESWL): Evidence from a prospective study. BJU Int 2012;110:E38-42. https://doi.org/10.1111/i.1464-410X.2012.10964.x

61. Yamashita S, Kohijimoto Y, Iguchi T, et al. Variation coefficient of stone density: A novel predictor of the outcome of extracorporeal shockwave lithotripsy. J Endourol 2017;31:384-90. https://doi.org/10.1089/ end.2016.0719

62. Perks AE, Schuler TD, Lee J, et al. Stone attenuation and skin-to-stone distance on computed tomography predicts for stone fragmentation by shockwave lithotripsy. Urology 2008;72:765-9. https://doi. org/10.1016/i.urology.2008.05.046

63. Wiesenthal JD, Ghiculete D, D'A Honey RJ, et al. Evaluating the importance of mean stone density and skin-to-stone distance in predicting successful shockwave lithotripsy of renal and ureteric calculi. Urol Res 2010;38:307-13. https://doi.org/10.1007/s00240-010-0295-0

64. Pareek G, Hedican SP, Lee FT, et al. Shockwave lithotripsy success determined by skin-to-stone distance on computed tomography. Urology 2005;66:941-4. https://doi.org/10.1016/i.urology.2005.05.011

65. Müllhaupt G, Engeler DS, Schmid HP, et al. How do stone attenuation and skin-to-stone distance in computed tomography influence the performance of shockwave lithotripsy in ureteral stone disease? BMC Urol 2015;15:72. https://doi.org/10.1186/s12894-015-0069-7

66. Wiesenthal JD, Ghiculete D, Ray AA, et al. A clinical nomogram to predict the successful shockwave lithotripsy of renal and ureteral calculi. J Urol 2011;186:556-62. https://doi.org/10.1016/i. juro.2011.03.109

67. Patel I, Kozakowski K, Hruby G, et al. Skin to stone distance is an independent predictor of stonefree status following shockwave lithotripsy. J Endourol 2009;23:1383-5. https://doi.org/10.1089/ end.2009.0394

68. McAteer JA, Evan AR, Williams JC, et al. Treatment protocols to reduce renal injury during shockwave lithotripsy. Curr Opin Urol 2009;19:192-5. https://doi.org/10.1097/MOU.0b013e32831e16e3

69. Lambert EH, Walsh R, Moreno MW, et al. Effect of escalating versus fixed voltage treatment on stone comminution and renal injury during extracorporeal shockwave lithotripsy: A prospective randomized trial. J Urol 2010;183:580-4. https://doi.org/10.1016/i.juro.2009.10.025

70. Willis $L R$, Evan $A P$, Connors $B A$, et al. Prevention of lithotripsy-induced renal injury by pre-treating kidneys with low-energy shockwaves. J Am Soc Nephrol 2006;17:663-73. https://doi.org/10.1681/ ASN.2005060634 
71. Weizer AZ, Zhong P, Preminger GM. new concepts in shockwave lithotripsy. Urol Clin North Am 2007;34:375-82. https://doi.org/10.1016/j.ucl.2007.07.002

72. Seemann 0, Rassweiler J, Chvapil $M$, et al. The effect of single shockwaves on the vascular system of artificially perfused rabbit kidneys. J Stone Dis 1993;5:172-8.

73. Pace KT, Weir MJ, Tariq N, et al. Low success rate of repeat shockwave lithotripsy for ureteral stones after failed initial treatment. J Urol 2000;164:1905-7. https://doi.org/10.1016/S0022-5347(05)66914-5

74. Rassweiler JJ, Knoll T, Köhrmann KU, et al. Shockwave technology and application: An update. Eur Urol 2011;59:784-96. https://doi.org/10.1016/i.eururo.2011.02.033

75. Pace KT, Ghiculete D, Hariu M, et al. Shockwave lithotripsy at 60 or 120 shocks per minute: A randomized, double-blind trial. J Urol 2005;174:595-9. https://doi.org/10.1097/01.ju.0000165156.90011.95

76. Honey RJDA, Schuler TD, Ghiculete D, et al. A randomized, double-blind trial to compare shockwave frequencies of 60 and 120 shocks per minute for upper ureteral stones. J Urol 2009;182:1418-23. https://doi.org/10.1016/i.juro.2009.06.019

77. Davenport K, Minervini A, Keoghane $S$, et al. Does rate matter? The results of a randomized controlled trial of 60 vs. 120 shocks per minute for shockwave lithotripsy of renal calculi. J Urol 2006;176:2055-8. https://doi.org/10.1016/i.juro.2006.07.012

78. Madbouly K, El-Tiraifi AM, Seida M, et al. Slow vs. fast shockwave lithotripsy rate for urolithiasis: A prospective randomized study. J Urol 2005;173:127-30. https://doi.org/10.1097/01. ju.0000147820.36996.86

79. Yilmaz E, Batislam E, Basar M, et al. Optimal frequency in extracorporeal shockwave lithotripsy: Prospective randomized study. Urology 2005;66:1160-4. https://doi.org/10.1016/i.urology.2005.06.111

80. Li K, Lin T, Zhang C, et al. Optimal frequency of shockwave lithotripsy in urolithiasis treatment: A systematic review and meta-analysis of randomized controlled trials. J Urol 2013;190:1260-7. https://doi.org/10.1016/i.juro.2013.03.075

81. Kato Y, Yamaguchi S, Hori J, et al. Improvement of stone comminution by slow delivery rate of shockwaves in extracorporeal lithotripsy. Int J Urol 2006;13:1461-5. https://doi.org/10.1111/i.14422042.2006.01609.x

82. Chacko J, Moore M, Sankey N, et al. Does a slower treatment rate impact the efficacy of extracorporeal shockwave lithotripsy for solitary kidney or ureteral stones? J Urol 2006;175:1370-4. https://doi.org/10.1016/S0022-5347(05)00683-X

83. Kang DH, Cho KS, Ham WS, et al. Comparison of high, intermediate, and low frequency shockwave lithotripsy for urinary tract stone disease: Systematic review and network meta-analysis. PLoS One 2016;11:e0158661. https://doi.org/10.1371/journal.pone.0158661

84. López-Acón JD, Alba AB, Bahilo-Mateu P, et al. Analyssis of the efficacy and safety of increasing the energy dose applied per session by increasing the number of shockwaves in extracorporeal lithotripsy: A prospective and comparative study. J Endourol 2017;31:1289-94. htrps://doi.org/10.1089/end.2017.0261

85. Budía Alba A, López Acón JD, Polo-Rodrigo A, et al. Analysis of the safety profile of treatment with a large number of shockwaves per session in extracorporeal lithotripsy. Actas Urol Esp 2015;39:291-5. https://doi.org/10.1016/i.acuro.2014.12.001

86. Eryildirim B, Sahin C, Tuncer $M$, et al. Medical expulsive therapy following shockwave lithotripsy in ureteral calculi: An effective approach for the improvement of health-related quality of life. Urol Int 2016;97:260-5. https://doi.org/10.1159/000446002

87. Ahmed A, Shalaby E, El-feky M, et al. Role of tamsulosin therapy after extracorporeal shockwave lithotripsy for renal stones: randomized controlled trial. Urol Int 2016;97:266-72. hitps://doi.org/10.1159/000445840

88. De Nunzio C, Brassetti A, Bellangino $M$, et al. Tamsulosin or silodosin adjuvant treatment is ineffective in improving shockwave lithotripsy outcome: A short-term followup randomized, placebo-controlled study. I Endourol 2016;30:817-21. https://doi.org/10.1089/end.2016.0113

89. Schuler TD, Shahani R, Honey RJDA, et al. Medical expulsive therapy as an adjunct to improve shockwave lithotripsy outcomes: A systematic review and meta-analysis. J Endourol 2009;23:387-93. https://doi.org/10.1089/end.2008.0216

90. Bhagat SK, Chacko NK, Kekre NS, et al. Is there a role for tamsulosin in shockwave lithotripsy for rena and ureteral calculi? J Urol 2007;177:2185-8. hitps://doi.org/10.1016/i.juro.2007.01.160

91. Gravina GL, Costa AM, Ronchi P, et al. Tamsulosin treatment increases clinical success rate of single extracorporeal shockwave lithotripsy of renal stones. Urology 2005;66:24-8. https://doi.org/10.1016/i. urology.2005.01.013

92. Porpiglia $F$, Destefanis $P$, Fiori $C$, et al. Role of adjunctive medical therapy with nifedipine and deflazacort after extracorporeal shockwave lithotripsy of ureteral stones. Urology 2002;59:835-8. https://doi.org/10.1016/S0090-4295(02)01553-4

93. Skolarikos A, Grivas N, Kallidonis P, et al. The efficacy of medical expulsive therapy (MET) in improving stone-free rate and stone expulsion time, after extracorporeal shockwave lithotripsy (SWL) for upper urinary stones: A systematic review and meta-analysis. Urology 2015;86:1057-64. https://doi.org/10.1016/i. urology.2015.09.004
94. Li M, Wang Z, Yang J, et al. Adjunctive medical therapy with innodataalpha-blocker after extracorporeal shockwave lithotripsy of renal and ureteral stones: A meta-analysis. PLoS One 2015;10. https://doi.org/10.1371/journal.pone.0122497

95. Chen $\mathrm{K}, \mathrm{Mi} \mathrm{H}, \mathrm{Xu}$ G, et al. The efficacy and safety of tamsulosin combined with extracorporeal shockwave lithotripsy for urolithiasis: A systematic review and meta-analysis of randomized controlled trials. J Endourol 2015;29:1166-76. https://doi.org/10.1089/end.2015.0098

96. Ouyang W, Sun G, Long $G$, et al. Adjunctive medical expulsive therapy with tamsulosin for repeated extracorporeal shockwave lithotripsy: A systematic review and meta-analysis. Int Braz I Urol 2020;47:2335. https://doi.org/10.1590/s1677-5538.ibju.2020.0093

97. Oestreich MC, Vernooij RW, Sathianathen NJ, et al. Alpha-blockers after shockwave lithotripsy for renal or ureteral stones in adults. Cochrane Database Syst Rev 2020;11:CD013393. https://doi.org/10.1002/14651858.CD013393.pub2

98. Musa AAK. Use of double-J stents prior to extracorporeal shockwave lithotripsy is not beneficial: Results of a prospective randomized study. Int Urol Nephrol 2008;40:19-22. https://doi.org/10.1007/s11255006-9030-8

99. Pettenati C, Fegoun AB El, Hupertan V, et al. Double I stent reduces the efficacy of extracorporeal shockwave lithotripsy in the treatment of lumbar ureteral stones. Cent Eur J Urol 2013;66:309-13. https://doi.org/10.5173/ceju.2013.03.art14

100. Pengfei S, Min J, Jie Y, et al. Use of ureteral stent in extracorporeal shockwave lithotripsy for upper urinary calculi: A systematic review and meta-analyssis. J Urol 2011;186:1328-35. https://doi.org/10.1016/i. juro.2011.05.073

101. Wang H, Man L, Li G, et al. Meta-analysis of stenting vs. non-stenting for the treatment of ureteral stones. PLOS One 2017;12:e0167670. https://doi.org/10.1371/journal.pone.0167670

102. Sfoungaristos S, Polimeros N, Kavouras A, et al. Stenting or not prior to extracorporeal shockwave lithotripsy for ureteral stones? Results of a prospective randomized study. Int Urol Nephrol 2012;44:731-7. https://doi.org/10.1007/s11255-011-0062-3

103. Lucio II J, Korkes F, Lopes-Neto AC, et al. Steinstrasse predictive factors and outcomes after extracorporeal shockwave lithotripsy. Int Braz J Urol 2011;37:477-82. https://doi.org/10.1590/S167755382011000400006

104. Duvdevani $M$, Lorber $G$, Gofrit $O N$, et al. Fever after shockwave lithotripsy-risk factors and indications for prophylactic antimicrobial treatment. J Endourol 2010;24:277-81. https://doi.org/10.1089/ end.2009.0283

105. Assimos D, Krambeck A, Miller NL, et al. Surgical management of stones: American Urological Association/ Endourological Society guideline, Part I. J Urol 2016;196:1153-60. https://doi.org/10.1016/i. juro.2016.05.090

106. Alsaikhan B, Koziarz A, Lee JY, et al. Preoperative alpha-blockers for ureteroscopy for ureteral stones: A systematic review and meta-analysis of randomized controlled trials. J Endourol 2020;34:33-41. https:// doi.org/10.1089/end.2019.0520

107. Brisbane W, Bailey MR, Sorensen MD. An overview of kidney stone imaging techniques. Nat Rev Urol 2016;13:654-62. https://doi.org/10.1038/nrurol.2016.154

108. Chew BH, Brotherhood HL, Sur RL, et al. Natural history, complications, and re-intervention rates of asymptomatic residual stone fragments after ureteroscopy: A report from the EDGE research consortium. J Urol 2016;195:982-6. htrps://doi.org/10.1016/i.juro.2015.11.009

109. Beiko DT, Beasley KA, Koka PK, et al. Upper tract imaging after ureteroscopic holmium:YAG laser lithotripsy: When is it necessary? Can J Urol 2003;10:2062-7.

110. Sutherland TN, Pearle MS, Lotan Y. How much is a kidney worth? Cost-effectiveness of routine imaging after ureteroscopy to prevent silent obstruction. J Urol 2013;189:2136-41. https://doi.org/10.1016/i. juro.2012.12.059

111. Weizer AZ, Auge BK, Silverstein AD, et al. Routine postoperative imaging is important after ureteroscopic stone manipulation. J Urol 2002;168:46-50. https://doi.org/10.1097/00005392-20020700000013

112. May PC, Hsi RS, Tran H, et al. The morbidity of ureteral strictures in patients with prior ureteroscopic stone surgery: Multi-institutional outcomes. J Endourol 2018;32:309-14. https://doi.org/10.1089/ end.2017.0657

113. Traxer 0 , Thomas A. Prospective evaluation and classification of ureteral wall iniuries resulting from insertion of a ureteral access sheath during retrograde intrarenal surgery. J Urol 2013;189:580-4. https://doi. org/10.1016/i.juro.2012.08.197

114. Traxer 0 , Wendt-Nordahl $G$, Sodha $H$, et al. Differences in renal stone treatment and outcomes for patients treated either with or without the support of a ureteral access sheath: The Clinical Research Office of the Endourological Society Ureteroscopy global study. World J Urol 2015;33:2137-44. https://doi. org/10.1007/s00345-015-1582-8

115. Huang J, Zhao Z, AlSmadi JK, et al. Use of the ureteral access sheath during ureteroscopy: A systematic review and meta-analysis. PLoS One 2018;13:e0193600. https://doi.org/10.1371/journal. pone. 0193600 
116. De Coninck V, Keller EX, Rodríguez-Monsalve M, et al. Systematic review of ureteral access sheaths: facts and myths. BJU Int 2018;122:959-69. https://doi.org/10.1111/bju.14389

117. Stern KL, Loftus CJ, Doizi S, et al. A prospective study analyzing the association between high-grade ureteral access sheath injuries and the formation of ureteral strictures. J Urol 2019;202:454. htrps:// doi.org/10.1016/i.urology.2019.02.032

118. Cetti RJ, Biers S, Keoghane SR. The difficult ureter: what is the incidence of pre-stenting? Ann R Coll Surg Engl 2011;93:31-3. https://doi.org/10.1308/003588411X12851639106990

119. Assimos D, Crisci A, Culkin D, et al. Preoperative JJ stent placement in ureteric and renal stone treatment: Results from the Clinical Research Office of Endourological Society (CROES) ureteroscopy (URS) global study. BJU Int 2016;117:648-54. https://doi.org/10.1111/bju.13250

120. Jessen JP, Breda A, Brehmer $M$, et al. International collaboration in endourology: Multicenter evaluation of pre-stenting for ureterorenoscopy. J Endourol 2016;30:268-73. https://doi.org/10.1089/ end.2015.0109

121. Netsch C, Knipper S, Bach T, et al. Impact of preoperative ureteral stenting on stone-free rates of ureteroscopy for nephroureterolithiasis: A matched-paired analysis of 286 patients. Urology 2012;80:1214-20. https://doi.org/10.1016/i.urology.2012.06.064

122. Chu L, Farris CA, Corcoran AT, et al. Preoperative stent placement decreases cost of ureteroscopy. Urology 2011;78:309-13. https://doi.org/10.1016/i.urology.2011.03.055

123. Chu L, Sternberg KM, Averch TD. Preoperative stenting decreases operative time and re-operative rates of ureteroscopy. J Endourol 2011;25:751-4. https://doi.org/10.1089/end.2010.0400

124. Pengfei S, Yutao L, Jie Y, et al. The results of ureteral stenting after ureteroscopic lithotripsy for ureteral calculi: A systematic review and meta-analysis. J Urol 2011;186:1904-9. https://doi.org/10.1016/i. juro.2011.06.066

125. Ordonez M, Hwang EC, Borofsky M, et al. Ureteral stent vs. no ureteral stent for ureteroscopy in the management of renal and ureteral calculi. Cochrane Database Syst Rev 2019;2019:CD012703. hitps:// doi.org/10.1002/14651858.CD012703.pub2

126. Pais VM, Smith RE, Stedina EA, et al. Does omission of ureteral stents increase risk of unplanned return visit? A systematic review and meta-analysis. J Urol 2016;196:1458-66. https://doi.org/10.1016/i. juro.2016.05.109

127. Mittakanti HR, Conti SL, Pao AC, et al. Unplanned emergency department visits and hospital admissions following ureteroscopy: do ureteral stents make a difference? Urology 2018;117:44-9. hittps://doi. org/10.1016/i.urology.2018.03.019

128. Torricelli $F C$, De $S$, Hinck B, et al. Flexible ureteroscopy with a ureteral access sheath: When to stent? Urology 2014;83:278-81. https://doi.org/10.1016/..urology.2013.10.002

129. Rapoport D, Perks AE, Teichman JMH. Ureteral access sheath use and stenting in ureteroscopy: Effect on unplanned emergency room visits and cost. J Endourol 2007;21:993-7. https://doi.org/10.1089/ end.2006.0236

130. Cevik I, Dillioglugil 0, Akdas A, et al. Is stent placement necessary after uncomplicated ureteroscopy for removal of impacted ureteral stones? J Endourol 2010;24:1263-7. https://doi.org/10.1089/ end.2009.0153

131. Denstedt JD, Wollin TA, Sofer M, et al. A prospective randomized controlled trial comparing non-stented vs. stented ureteroscopic lithotripsy. J Urol 2001;165:1419-22. hittps://doi.org/10.1016/S00225347(05) 66320-3

132. Damiano R, Autorino R, De Sio M, et al. Effect of tamsulosin in preventing ureteral stent-related morbidity: A prospective study. J Endourol 2008;22:651-5. https://doi.org/10.1089/end.2007.0257

133. El-Nahas AR, Tharwat $M$, Elsaadany $M$, et al. A randomized controlled trial comparing alpha blocker (tamsulosin) and anticholinergic (solifenacin) in treatment of ureteral stent-related symptoms. World J Urol 2016;34:963-8. htrps://doi.org/10.1007/s00345-015-1704-3

134. Lallas CD, Auge BK, Raj GV, et al. Laser Doppler flowmetric determination of ureteral blood flow after ureteral access sheath placement. J Endourol 2002;16:583-90. https://doi. org/10.1089/089277902320913288

135. Paul CJ, Brooks NA, Ghareeb GM, et al. pilot study to determine optimal stent duration following ureteroscopy: Three vs. seven days. Curr Urol 2017;11:97-102. https://doi.org/10.1159/000447201

136. Kumar A, Nanda B, Kumar N, et al. A prospective randomized comparison between shockwave lithotripsy and semirigid ureteroscopy for upper ureteral stones $<2 \mathrm{~cm}$ : A single-center experience. J Endourol 2015;29:47-51. https://doi.org/10.1089/end.2012.0493

137. Scotland KB, Safaee Ardekani G, Chan JYH, et al. Total surface area influences stone-free outcomes in shockwave lithotripsy for distal ureteral calculi. J Endourol 2019;33:661-6. https://doi.org/10.1089/ end.2019.0120

138. Hautmann S, Friedrich MG, Fernandez S, et al. Extracorporeal shockwave lithotripsy compared with ureteroscopy for the removal of small distal ureteral stones. Urol Int 2004;73:238-43. hitps://doi. org/10.1159/000080834
139. Verze P, Imbimbo C, Cancelmo G, et al. Extracorporeal shockwave lithotripsy vs. ureteroscopy as firstline therapy for patients with single, distal ureteric stones: A prospective randomized study. BJU Int 2010;106:1748-52. https://doi.org/10.1111/j.1464-410X.2010.09338.x

140. Matlaga BR, Jansen JP, Meckley LM, et al. Treatment of ureteral and renal stones: A systematic review and meta-analysis of randomized, controlled trials. J Urol 2012;188:130-7. htrps://doi.org/10.1016/i. juro.2012.02.2569

141. Drake T, Grivas N, Dabestani S, et al. What are the benefits and harms of ureteroscopy compared with shockwave lithotripsy in the treatment of upper ureteral stones? A systematic review. Eur Urol 2017:72:772-86. https://doi.org/10.1016/i.eururo.2017.04.016

142. Rebuck DA, Coleman S, Chen JF, et al. Extracorporeal shockwave lithotripsy vs. ureteroscopy: A comparison of intraoperative radiation exposure during the management of nephrolithiasis. J Endourol 2012;26:597601. hittps://doi.org/10.1089/end.2011.0185

143. Cone EB, Pareek G, Ursiny M, et al. Cost-effectiveness comparison of ureteral calculi treated with ureteroscopic laser lithotripsy vs. shockwave lithotripsy. World J Urol 2017;35:161-6. https://doi.org/10.1007/ s00345-016-1842-2

144. Constanti M, Calvert RC, Thomas K, et al. Cost analysis of ureteroscopy (URS) vs. extracorporeal shockwave lithotripsy (ESWL) in the management of ureteric stones $<10 \mathrm{~mm}$ in adults: A U.K. perspective. BJU Int 2020;125:457-66. https://doi.org/10.1111/bju.14938

145. Penniston KL, Nakada SY. Health-related quality of life differs between male and female stone formers. J Urol 2007;178:2435-40. hitps://doi.org/10.1016/i.juro.2007.08.009

146. Diniz DHMP, Blay SL, Schor N. Quality of life of patients with nephrolithiasis and recurrent painful renal colic. Nephron Clin Pract 2007;106. hittps://doi.org/10.1159/000102995

147. Bensalah K, Tuncel A, Gupta A, et al. Determinants of quality of life for patients with kidney stones. J Urol 2008;179:2238-43. https://doi.org/10.1016/i.juro.2008.01.116

148. Donnally CJ, Gupta A, Bensalah K, et al. Longitudinal evaluation of the SF-36 quality of life questionnaire in patients with kidney stones. Urol Res 2011;39:141-6. https://doi.org/10.1007/s00240-010-0313-2

149. Bryant $M$, Angell J, Tu H, et al. Health related quality of life for stone formers. J Urol 2012;188:436-40. https://doi.org/10.1016/i.juro.2012.04.015

150. Chandrasekar T, Monga $M$, Nguyen $M$, et al. Internet-based patient survey on urolithiasis treatment and patient satisfaction. J Endourol 2015;29:725-9. https://doi.org/10.1089/end.2014.0643

151. Park J, Shin DW, Chung JH, et al. Shockwave lithotripsy versus ureteroscopy for ureteral calculi: A prospective assessment of patient-reported outcomes. World J Urol 2013;31:1569-74. https://doi. org/10.1007/s00345-012-0966-2

152. Lee JH, Woo SH, Kim ET, et al. Comparison of patient satisfaction with treatment outcomes between ureteroscopy and shockwave lithotripsy for proximal ureteral stones. Korean I Urol 2010;51:788-93. https://doi.org/10.4111/kju.2010.51.11.788

153. Ghalayini IF, Al-Ghazo MA, Khader YS. Extracorporeal shockwave lithotripsy vs. ureteroscopy for distal ureteric calculi: efficacy and patient satisfaction. Int Braz J Urol 2006;32:656-64. https://doi. org/10.1590/S1677-55382006000600006

154. Rabah DM, Alomar M, Binsaleh S, et al. Health-related quality of life in ureteral stone patients: Postureterolithiasis. Urol Res 2011;39:385-8. https://doi.org/10.1007/s00240-011-0375-9

155. Izamin I, Aniza I, Rizal AM, et al. Comparing extracorporeal shockwave lithotripsy and ureteroscopy for treatment of proximal ureteric calculi: a costeffectiveness study. Med J Malaysia 2009;64:12-21. https:// pubmed.ncbi.nlm.nih.gov/19852314/

156. Hamamoto $S$, Unno R, Taguchi K, et al. Determinants of health-related quality of life for patients after urinary lithotripsy: Ureteroscopic vs. shockwave lithotripsy. Urolithiasis 2018;46:203-10. https://doi. org/10.1007/s00240-017-0972-3

157. Ceylan Y, Ucer 0 , Bozkurt 0 , et al. The effect of SWL and URS on health-related quality of life in proximal ureteral stones. Minim Invasive Ther Allied Technol 2018;27:148-52. https://doi.org/10.1080/13 645706.2017.1350719

158. Raja A, Hekmati Z, Joshi HB. How do urinary calculi influence health-related quality of life and patient treatment preference: A systematic review. J Endourol 2016;30:727-43. https://doi.org/10.1089/ end.2016.0110

159. Alsaikhan B, Andonian S. Shockwave lithotripsy in patients requiring anticoagulation or antiplatelet agents. Can Urol Assoc J 201 1;5:53-7. https://doi.org/10.5489/cuaj.09140

160. Aboumarzouk OM, Somani BK, Monga M. Flexible ureteroscopy and holmium:YAG laser lithotripsy for stone disease in patients with bleeding diathesis: A systematic review of the literature. Int Braz I Urol 2012;38:298-305. https://doi.org/10.1590/S1677-55382012000300002

161. Klingler HC, Kramer G, Lodde M, et al. Stone treatment and coagulopathy. Eur Urol 2003;43:75-9. https://doi.org/10.1016/S0302-2838(02)00538-9

162. Razvi H, Fuller A, Nott L, et al. Risk factors for perinephric hematoma formation after shockwave lithotripsy: A matched case-control analysis. J Endourol 2012;26:1478-82. https://doi.org/10.1089/ end.2012.0261 
163. Tsuboi T, Fuïta T, Maru N, et al. Transurethral ureterolithotripsy and extracorporeal shockwave lithotripsy in patients with idiopathic thrombocytopenic purpura. Acta Urol Jpn 2008;54:17-22.

164. Kaatz S, Paje D. Update in bridging anticoagulation. J Thromb Thrombolysis 2011;31:259-64. https:// doi.org/10.1007/s11239-011-0571-z

165. Schregel C, John H, Randazzo M, et al. Influence of acetylsalicylic acid and low-molecular weight heparins on the formation of renal hematoma after shockwave lithotripsy. World J Urol 2017;35:1939-46. https:// doi.org/10.1007/s00345-017-2070-0

166. Schnabel MJ, Gierth M, Bründl J, et al. Antiplatelet and anticoagulative medication during shockwave lithotripsy. J Endourol 2014;28:1034-9. https://doi.org/10.1089/end.2014.0162

167. Kuo RL, Aslan P, Fitzgerald KB, et al. Use of ureteroscopy and holmium:YAG laser in patients with bleeding diatheses. Urology 1998;52:609-13. https://doi.org/10.1016/S0090-4295(98)00276-3

168. Watterson JD, Girvan AR, Cook AJ, et al. Safety and efficacy of holmium:YAG laser lithotripsy in patients with bleeding diatheses. J Urol 2002; 168:442-5. https://doi.org/10.1016/S0022-5347(05)64654-X

169. Turna B, Stein RJ, Smaldone MC, et al. Safety and efficacy of flexible ureterorenoscopy and holmium:YAG lithotripsy for intrarenal stones in anticoagulated cases. J Urol 2008;179:1415-9. https://doi. org/10.1016/i.juro.2007.11.076

170. Sharaf A, Amer T, Somani BK, et al. Ureteroscopy in patients with bleeding diatheses, anticoagulated, and on anti-platelet agents: A systematic review and meta-analysis of the literature. J Endourol 2017;31:121725. htrps://doi.org/10.1089/end.2017.0253

171. Elkoushy MA, Violette PD, Andonian S. Ureteroscopy in patients with coagulopathies is associated with lower stone-free rate and increased risk of clinically significant hematuria. Int Braz I Urol 2012;38:195202. https://doi.org/10.1590/S1677-55382012000200007

172. Kumar V, Ahlawat R, Banjeree GK, et al. Percutaneous ureterolitholapaxy: The best bet to clear large bulk impacted upper ureteral calculi. Arch Esp Urol 1996;49:86-91.

173. Rhee BK, Bretan Jr PN, Stoller ML. Urolithiasis in renal and combined pancreas/renal transplant recipients. J Urol 1999;161:1458-62. htrps://doi.org/10.1016/S0022-5347(05)68926-4

174. Okhunov Z, Duty B, Smith AD, et al Management of urolithiasis in patients after urinary diversions. BJU Int 2011;108:330-6. https://doi.org/10.1111/i.1464-410X.2011.10194.x

175. Fernandez A, Foell K, Nott L, et al. Percutaneous nephrolithotripsy in patients with urinary diversions: A casecontrol comparison of perioperative outcomes. J Endourol 2011;25:1615-8. https://doi.org/10.1089/ end.2011.0045

176. Maheshwari PN, Oswal AT, Andankar M, et al. Is antegrade ureteroscopy better than retrograde ureteroscopy for impacted large upper ureteral calculi? J Endourol 1999;13:441-4. https://doi.org/10.1089/ end.1999.13.441

177. Goel R, Aron M, Kesarwani PK, et al. Percutaneous antegrade removal of impacted upper-ureteral calculi: Still the treatment of choice in developing countries. J Endourol 2005;19:54-7. https://doi. org/10.1089/end.2005.19.54

178. Karami H, Arbab AHMM, Hosseini SJ, e al. Impacted upper-ureteral calculi $>1 \mathrm{~cm}$ : Blind access and totally tubeless percutaneous antegrade removal or retrograde approach? J Endourol 2006;20:616-9. https:// doi.org/10.1089/end.2006.20.616

179. Topaloglu H, Karakoyunlu N, Sari S, et al. A comparison of antegrade percutaneous and laparoscopic approaches in the treatment of proximal ureteral stones. Biomed Res Int 2014;2014. https://doi. org/10.1155/2014/691946

180. Zhu H, Ye X, Xiao X, et al. Retrograde, antegrade, and laparoscopic approaches to the management of large upper ureteral stones after shockwave lithotripsy failure: A four-year retrospective study. J Endourol 2014;28:100-3. https://doi.org/10.1089/end.2013.0391

181. Sfoungaristos $S$, Mykoniatis I, lsid A, et al. Retrograde vs. antegrade approach for the management of large proximal ureteral stones. Biomed Res Int 2016;2016. https://doi.org/10.1155/2016/6521461

182. Dwyer ME, Krambeck AE, Bergstralh EJ, et al. Temporal trends in incidence of kidney stones among children: A 25-year population-based study. J Urol 2012;188:247-52. https://doi.org/10.1016/i. juro.2012.03.021

183. Routh JC, Graham DA, Nelson CP. Epidemiological trends in pediatric urolithiasis at United States freestanding pediatric hospitals. J Urol 2010;184:1100-5. https://doi.org/10.1016/i.juro.2010.05.018

184. Ellison JS, Yonekawa K. Recent advances in the evaluation, medical, and surgical management of pediatric nephrolithiasis. Curr Pediatr Rep 2018;6:198-208. https://doi.org/10.1007/s40124-018-0176-5

185. Radmayr C, Bogaert G, Dogan HS, et al. EAU guidelines on pediatric urology, 2018. Available at: https://uroweb.org/wp-content/uploads/EAU-Guidelines-on-Paediatric-Urology-2018-large-text.pdf. Accessed August 21, 2021.

186. Fulgham PF, Assimos DG, Pearle MS, et al. Clinical effectiveness protocols for imaging in the management of ureteral calculous disease: AUA technology assessment. J Urol 2013;189:1203-13. https:// doi.org/10.1016/i.juro.2012.10.031

187. Rob S, Jones P, Pietropaolo A, et al. Ureteroscopy for stone disease in pediatric population is safe and effective in medium-volume and high-volume centers: Evidence from a systematic review. Curr Urol Rep 2017;18. https://doi.org/10.1007/s11934-017-0742-3
188. Jones P, Rob S, Griffin S, et al. Outcomes of ureteroscopy (URS) for stone disease in the pediatric population: Results of over 100 URS procedures from a UK tertiary center. World J Urol 2020;38:213-8. https://doi.org/10.1007/s00345-019-02745-3

189. Johnson EK, Graham DA, Chow JS, et al. Nationwide emergency department imaging practices for pediatric urolithiasis: Room for improvement. J Urol 2014;192:200-6. https://doi.org/10.1016/i. juro.2014.01.028

190. Ziemba JB, Canning DA, Lavelle J, et al. Patient and institutional characteristics associated with initial computerized tomography in children presenting to the emergency department with kidney stones. J Urol 2015;193:1848-54. https://doi.org/10.1016/i.juro.2014.09.115

191. Strohmaier WL. Imaging in pediatric urolithiasis — what's the best choice? Trans/ Pediatr 2015;4:36-40.

192. Niemann T, Kollmann T, Bongartz G. Diagnostic performance of low-dose CT for the detection of urolithiasis: A meta-analysis. Am J Roentgenol 2008;191:396-401. https://doi.org/10.2214/AJR.07.3414

193. Barreto $L$, Jung JH, Abdelrahim $A$, et al. Medical and surgical interventions for the treatment of urinary stones in children. Cochrane Database Syst Rev 2018;2018(6). https://doi.org/10.1002/14651858. CD010784.pub2

194. Tasian GE, Cost NG, Granberg CF, et al. Tamsulosin and spontaneous passage of ureteral stones in children: A multi-institutional cohort study. J Urol 2014;192:506-11. https://doi.org/10.1016/i.juro.2014.01.091

195. Pietrow PK, Pope IV JC, Adams MC, et al. Clinical outcome of pediatric stone disease. J Urol 2002; 167:6703. https://doi.org/10.1097/00005392-200202000-00060

196. Kim SS, Kolon TF, Canter D, et al. Pediatric flexible ureteroscopic lithotripsy: The Children's Hospital of Philadelphia experience. J Urol 2008;180:2616-9. hitps://doi.org/10.1016/i.juro.2008.08.051

197. Velázquez N, Zapata D, Wang HHS, et al. Medical expulsive therapy for pediatric urolithiasis: Systematic review and meta-analysis. J Pediatr Urol 2015;11:321-7. https://doi.org/10.1016/i. jpurol.2015.04.036

198. Basiri A, Zare S, Shakhssalim N, et al. Ureteral calculi in children: What is best as a minimally invasive modality? Urol J 2008;5:67-73.

199. De Dominicis M, Matarazzo E, Capozza N, et al. Retrograde ureteroscopy for distal ureteric stone removal in children. BJU Int 2005;95:1049-52. https://doi.org/10.1111/i.1464-410X.2005.05464.x

200. Basiri A, Zare S, Tabibi A, et al. A multicenter, randomized, controlled trial of transureteral and shockwave lithotripsy: Which is the best minimally invasive modality to treat distal ureteral calculi in children? I Urol 2010;184:1106-9. https://doi.org/10.1016/i.uro.2010.05.021

201. Esmat $M$, Gareeb A, Hassan AT, et al. Flexible ureteroscopy with laser lithotripsy vs. extracorporeal shockwave lithotripsy in management of ureteric stones in pediatric age group. Egypt J Med Hosp 2018;72:5589-94 https://doi.org/10.21608/ejhm.2018.11515

202. Adam A. A simple and novel method to attain retrograde ureteral access after previous Cohen cross-trigonal ureteral re-implantation. Curr Urol 2017;11:42-7. https://doi.org/10.1159/000447193

203. Ishii H, Griffin S, Somani BK. Ureteroscopy for stone disease in the pediatric population: A systematic review. BJU Int 2015;115:867-73. https://doi.org/10.1111/bju.12927

204. Marchetti KA, Lee T, Raja N, et al. Extracorporeal shockwave lithotripsy vs. ureteroscopy for management of pediatric nephrolithiasis in upper urinary tract stones: Multi-institutional outcomes of efficacy and morbidity. J Pediatr Urol 2019;15:516.el-8. https://doi.org/10.1016/i.jpurol.2019.06.006

205. Dogan HS, Onal B, Satar N, et al. Factors affecting complication rates of ureteroscopic lithotripsy in children: Results of multi-institutional retrospective analysis by pediatric stone disease study group of Turkish pediatric urology society. J Urol 2011;186:1035-40. https://doi.org/10.1016/i.juro.2011.04.097

206. Elgammal MA, Safwat AS, Elderwy A, et al. Primary vs. secondary ureteroscopy for pediatric ureteral stones. J Pediatr Urol 2014;10:1193-8. https://doi.org/10.1016/i.jpurol.2014.05.010

207. Minevich E, DeFoor W, Reddy P, et al. Ureteroscopy is safe and effective in prepubertal children. I Urol 2005;174:276-9. https://doi.org/10.1097/01.ju.0000161212.69078.e6

208. Featherstone NC, Somani BK, Griffin SJ. Ureteroscopy and laser stone fragmentation (URSL) for large $(\geq 1 \mathrm{~cm})$ pediatric stones: Outcomes from a university teaching hospital. J Pediatr Urol 2017;13:202. el-7. https://doi.org/10.1016/i.jpurol.2016.07.006

209. Sarica K, Erturhan S, Yurtseven C, et al. Effect of potassium citrate therapy on stone recurrence and regrowth after extracorporeal shockwave lithotripsy in children. J Endourol 2006;20:875-9. https:// doi.org/10.1089/end.2006.20.875

210. Tasian GE, Kabarriti AE, Kalmus A, et al. Kidney stone recurrence among children and adolescents. J Urol 2017;197:246-52. https://doi.org/10.1016/i.juro.2016.07.090

211. Mullins JK, Semins MJ, Hyams ES, et al. Half Fourier single-shot turbo spin-echo magnetic resonance urography for the evaluation of suspected renal colic in pregnancy. Urology 2012;79:1252-5. https:// doi.org/10.1016/i.urology.2011.12.016

212. Bjazevic J, Razvi H. Stones in pregnancy and pediatrics. Asian J Urol 2018;5:223-34. https://doi. org/10.1016/i.ajur.2018.05.006

213. Regan F, Kuszyk B, Bohlman ME, et al. Acute ureteric calculus obstruction: Unenhanced spiral CT vs. HASTE MR urography and abdominal radiograph. BrJ Radiol 2005;78:506-11. https://doi.org/10.1259/ bir/22314006 
Lee et al

214. White WM, Johnson EB, Zite NB, et al. Predictive value of current imaging modalities for the detection of urolithiasis during pregnancy: A multicenter, longitudinal study. J Urol 2013;189:931-4. https://doi. org/10.1016/i.juro.2012.09.076

215. Masselli G, Derme M, Laghi F, et al. Imaging of stone disease in pregnancy. Abdom Imaging 2013;38:140914. https://doi.org/10.1007/s00261-013-0019-3

216. Semins MJ, Matlaga BR. Management of stone disease in pregnancy. Curr Opin Urol 2010;20:174-7. htrps://doi.org/10.1097/MOU.0b013e3283353a4b

217. Burdan F, Starostawska E, Szumito J. Prenatal tolerability of acetaminophen and other over-the-counter non-selective cyclooxygenase inhibitors. Pharmacol Reports 2012;64:521-7. https://doi.org/10.1016/ S1734-1140(12)70847-2

218. Bailey G, Vaughan L, Rose C, et al. Perinatal outcomes with tamsulosin therapy for symptomatic urolithiasis. J Urol 2016;195:99-103. hitps://doi.org/10.1016/i.juro.2015.06.097

219. Theriault $B$, Morin $F$, Cloutier J. Safety and efficacy of tamsulosin as medical expulsive therapy in pregnancy. World J Urol 2020;38:2301-26. https://doi.org/10.1007/s00345-019-03022-z

220. Semins MJ, Matlaga BR. Kidney stones during pregnancy. Nat Rev Urol 2014;11:163-8. https://doi. org/10.1038/nrurol.2014.17

221. White J, Ory J, Lantz Powers AG, et al. Urological issues in pregnancy: A review for urologists. Can Urol Assoc J 2020;14:352-7. https://doi.org/10.5489/cuai.6526

222. Khoo L, Anson K, Patel U. Success and short-term complication rates of percutaneous nephrostomy during pregnancy. J Vasc Interv Radiol 2004;15:1469-73. https://doi.org/10.1097/01. RVI.0000140639.57131.6D

223. Epelboym Y, Tivnan P, Desai K, et al. Percutaneous nephrostomy placement in pregnant patients: A retrospective single center experience. J Matern Neonatal Med 2020 Mar 19:1-5. https://doi.org/10 $.1080 / 14767058.2020 .1740673$

224. Thomas A, Cloutier J, Villa L, et al. Prospective analysis of a complete retrograde ureteroscopic technique with holmium laser stent cutting for management of encrusted ureteral stents. J Endourol 2017;31:47681. https://doi.org/10.1089/end.2016.0816

225. Denstedt JD, Razvi H. Management of urinary calculi during pregnancy. J Urol 1992;148:1072-4. https:// doi.org/10.1016/S0022-5347(17)36821-0

226. Akpinar H, Tüfek I, Alici B, et al. Ureteroscopy and holmium laser lithotripsy in pregnancy: Stents must be used postoperatively. J Endourol 2006;20:107-10. https://doi.org/10.1089/end.2006.20.107

227. Isen K, Hatipoglu NK, Dedeoglu S, et al. Experience with the diagnosis and management of symptomatic ureteric stones during pregnancy. Urology 2012;79:508-12. https://doi.org/10.1016/i urology.2011.10.023
228. Butticè S, Laganà AS, Vitale SG, et al. Ureteroscopy in pregnant women with complicated colic pain: Is there any risk of premature labor? Arch Ital di Urol e Androl 2017;89:287-92. https://doi.org/10.4081/ aiva.2017.4.287

229. Watterson JD, Girvan AR, Beiko DT, et al. Ureteroscopy and holmium:YAG laser lithotripsy: An emerging definitive management strategy for symptomatic ureteral calculi in pregnancy. Urology 2002;60:383-7. https://doi.org/10.1016/S0090-4295(02)01751-X

230. Bozkurt Y, Penbegul N, Soylemez H, et al. The efficacy and safety of ureteroscopy for ureteral calculi in pregnancy: Our experience in 32 patients. Urol Res 2012;40:531-5. https://doi.org/10.1007/ s00240-011-0454-y

231. Wang $Z$, Xu L, Su Z, Yao C, et al. Invasive management of proximal ureteral calculi during pregnancy. Urology 2014;83:745-9. https://doi.org/10.1016/i.urology.2013.11.031

232. Gerogescu D, Multescu R, Geavlete B, et al. Ureteroscopy — first-line treatment alternative in ureteral calculi during pregnancy? Chir 2014;109:229-32.

233. Tan ST, Chen $X$, Sun $M$, et al. The comparation of effects and security of double-J stent retention and ureteroscopy lithotripsy in the treatment of symptomatic ureteral calculi during pregnancy. Eur J Obstet Gynecol Reprod Biol 2018;227:32-4. https://doi.org/10.1016/i.ejogrb.2018.05.041

234. Semins MJ, Trock BJ, Matlaga BR. The safety of ureteroscopy during pregnancy: A systematic review and meta-analysis. J Urol 2009;181:139-43. https://doi.org/10.1016/i.juro.2008.09.029

235. Cheek TG, Baird E. Anesthesia for non-obstetric surgery: Maternal and fetal considerations. Clin Obstet Gynecol 2009;52:535-45. https://doi.org/10.1097/GRF.0b013e3181c1 1f60

236. Cocuzza M, Colombo JR, Lopes Rl, et al. Use of inverted fluoroscope's C-arm during endoscopic treatment of urinary tract obstruction in pregnancy: A practicable solution to cut radiation. Urology 2010;75:1505-8. https://doi.org/10.1016/i.urology.2009.12.014

237. Frankenschmidt A, Sommerkamp H. Shockwave lithotripsy during pregnancy: A successful clinical experiment. J Urol 1998;159:501-2. https://doi.org/10.1016/S0022-5347 (01)63962-4

238. Shah A, Chandak P, Tiptaft R, et al. Percutaneous nephrolithotomy in early pregnancy. Int I Clin Pract 2004:58:809-10. https://doi.org/10.1111/j.1368-5031.2004.00047.x

Correspondence: Dr. Jason Y. Lee, Division of Urology, Department of Surgery, University of Toronto, Toronto, 0N, Canada; jasonleeuoft@gmail.com 